Article

\title{
The NAC Protein from Tamarix hispida, ThNAC7, Confers Salt and Osmotic Stress Tolerance by Increasing Reactive Oxygen Species Scavenging Capability
}

\author{
Zihang He ${ }^{1}$, Ziyi Li ${ }^{1}$, Huijun Lu ${ }^{1}$, Lin Huo ${ }^{2}$, Zhibo Wang ${ }^{1}$, Yucheng Wang ${ }^{1}$ and Xiaoyu Ji ${ }^{1, *(\mathbb{D})}$ \\ 1 State Key Laboratory of Tree Genetics and Breeding (Northeast Forestry University), Harbin 150040, China \\ 2 Key Laboratory of Biogeography and Bioresource in Arid Land, Xinjiang Institute of Ecology and \\ Geography, Chinese Academy of Sciences, Urumqi 830011, China \\ * Correspondence: jixiaoyu@nefu.edu.cn; Tel./Fax: +86-451-8219-0607
}

Received: 6 June 2019; Accepted: 8 July 2019; Published: 12 July 2019

check for updates

\begin{abstract}
Plant specific NAC (NAM, ATAF1/2 and CUC2) transcription factors (TFs) play important roles in response to abiotic stress. In this study, we identified and characterized a NAC protein, ThNAC7, from Tamarix hispida. ThNAC7 is a nuclear localized protein and has transcriptional activation activity. ThNAC7 expression was markedly induced by salt and osmotic stresses. Transiently transformed T. hispida seedlings overexpressing ThNAC7 (OE) or with RNA interference (RNAi) silenced ThNAC7 were generated to investigate abiotic stress tolerance via the gain- and lossof function. Overexpressing ThNAC7 showed an increased reactive oxygen species (ROS) scavenging capabilities and proline content, which was accomplished by enhancing the activities of superoxide dismutase (SOD) and peroxidase (POD) in transiently transformed T. hispida and stably transformed Arabidopsis plants. Additionally, ThNAC7 activated these physiological changes by regulating the transcription level of P5CS, SOD and POD genes. RNA-sequencing (RNA-seq) comparison between wild-type and ThNAC7-transformed Arabidopsis showed that more than 40 known salt tolerance genes might regulated by $T h N A C 7$, including stress tolerance-related genes and TF genes. The results indicated that ThNAC7 induces the transcription level of genes associated with stress tolerance to enhance salt and osmotic stress tolerance via an increase in osmotic potential and enhanced ROS scavenging.
\end{abstract}

Keywords: NAC transcription factor; Tamarix hispida; abiotic stress; ROS scavenging; transcription activation; transient expression

\section{Introduction}

Environmental constraints, including cold, salt and drought, which negatively affect the growth and development of plants, are leading large agricultural production losses worldwide [1]. Plants have evolved a wide range of adaptations to abiotic and biotic stresses, involving stress perception coupled with signal transduction and amplification [2]. In progress, TFs can regulate the expression of downstream functional genes involved in biotic or abiotic stress tolerance [3]. Recently, many researches have reported that a battery of TFs or functional genes involved in abiotic stress responses. For instance, overexpression of $A t b H L H 112$ increased salt and drought tolerance via increasing the expression level of PODs and SODs to improve ROS scavenging ability in Arabidopsis [4]. Overexpression of BplMYB46 in transgenic Betula platyphylla improved abiotic tolerance via enhancing the ROS scavenging and proline level [5]. Overexpressing of $V v W R K Y 30$ improved salinity stress resistance via regulating osmoticum accumulation and ROS scavenging in Arabidopsis [6]. Besides, the overexpression of OsDhn1 increased 
drought and salt tolerance via reducing ROS accumulation in transgenic rice [7]. The overexpression of AnnSp2 enhanced salt and drought tolerance by ABA synthesis and the elimination of ROS in transgenic tomato [8].

The NAC TF family is a plant specific TF family and includes 117 members in Arabidopsis thaliana, 163 in Populus trichocarpa, 151 in Oryza sativa, and 152 in both Nicotiana tabacum and Glycine max [9]. NAC proteins possess a nuclear localization signal sequence, which have variable C-terminal domain in addition to highly conserved $\mathrm{N}$-terminal binding domain [10].

In recent years, many studies have reported that a number of NAC TFs involved in biotic $[11,12]$ and abiotic [12,13] stress responses in plants. A relatively large proportion of rice and Arabidopsis NAC TFs under different abiotic and biotic stresses showed differential expression patterns by transcriptional analysis. [14,15]. Moreover, NAC TFs confer abiotic stress tolerance to transgenic plants. For instance, AtNAC72, AtNAC109, and AtNAC55 contribute to drought tolerance by promoting the detoxification of aldehydes in the glyoxalase pathway [16,17]. Transgenic rice plants overexpressing OsNAC2, OsNAC3, OsNAC6, or OsNAC14 enhanced drought tolerance [18-21]. The overexpression of OsNAC6 induced tolerance to high salt, drought and blast disease in rice [22]. Overexpression of TaNAC69 improved the expression of stress-related genes and drought tolerance in transgenic wheat plants [23]. Overexpression of TsNAC1 in both Thellungiella halophila and Arabidopsis could enhance abiotic stress resistance, particularly salt stress tolerance [24]. MusaNAC68 positively regulates salt and drought stress tolerance in transgenic banana plants [25]. Overexpression of $M d N A C 1$ enhanced drought stress tolerance via enhancing photosynthesis and ROS scavenging in apple transgenic plants [26]. Although a variety of NAC proteins in different plant species have been identified and reported to play key roles in abiotic stress, few studies have been performed about the biological functions of NAC TFs in halophytic woody plants.

Tamarix hispida, belong to the genus Tamarix, is a woody halophyte that it can grow better than other plants in drought and saline soils. T. hispida has properly effective stress defense system and is appropriately used to study abiotic stress tolerance. Previous study identified 16 NAC TFs in transcriptomes of T. hispida [27]. Among these NACs, we further identified a NAC gene, ThNAC7, which can respond to high levels of salt stress. Therefore, we selected ThNAC7 for further study. The results demonstrated that ThNAC7 regulates osmotic and salt stress tolerance via modulating the transcription levels of genes that may activate a number of physiological variations, containing ROS scavenging and changes in osmotic potential, in both transiently transformed T. hispida and stably transformed Arabidopsis plants. The present study offers new insights into the functions of NAC TFs in abiotic stress tolerance.

\section{Results}

\subsection{Bioinformatics Analysis of ThNAC7}

The open reading frame (ORF) of ThNAC7 is $1737 \mathrm{bp}$, encodes 578 amino acids with $65.13 \mathrm{kDa}$ molecular weight. Multiple sequence alignment analysis indicated that ThNAC7 and NAC proteins of other plant species shared highly conserved binding domain at the N-terminal. ThNAC7 contains a classic NAC domain that is the basic characteristic of the NAC family (Supplementary Figure S1). Phylogenetic tree was constructed in order to study the evolutionary relationships between ThNAC7 and other 105 NACs from Arabidopsis. The results showed that ThNAC7 is most similar to two Arabidopsis NAC proteins, ANAC091 (AT5G24590) and ANAC062 (AT3G49530) from NAC subfamily VI (Figure 1), indicating that ThNAC7 should also belong to the NAC subfamily VI.

ThNAC7 and 88 NACs from the transcriptomes of T. hispida were used for another phylogenetic tree to study the phylogenetic relationships of the NAC TF family in T. hispida. All NACs could be divided into 10 subfamilies (I-X), and ThNAC7 was most similar to ThNAC35, and belongs to NAC subfamily I (Figure S2). 


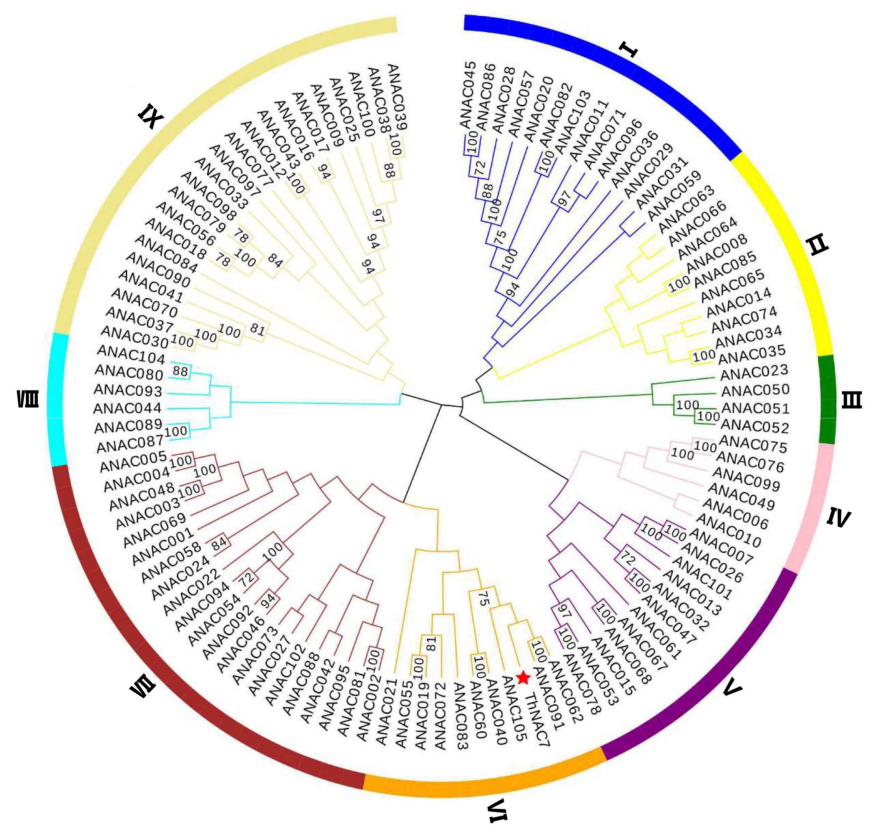

Figure 1. Phylogenetic analysis between ThNAC7 and the NAC proteins from Arabidopsis. The phylogenetic relationship of ThNAC7 and the NAC proteins from Arabidopsis. The ThNAC7 and 105 Arabidopsis NACs were aligned; the unrooted NJ tree was constructed using MEGA 6.06.

\subsection{ThNAC7 Is a Nuclear Localization Protein with Transactivation Activity}

The 35S::ThNAC7-GFP (green fluorescent protein) or 35S::GFP plasmid was respectively imported into onion epidermal cells via particle bombardment. Microscopic observation indicated that the 35S::ThNAC7-GFP fusion protein was observed exclusively in nucleus, while the 35S::GFP protein in the control was uniformly distributed throughout the cytoplasm and nucleus (Figure 2A). The results indicate $\mathrm{d}$ that ThNAC7 is a nuclear localization protein.

To confirm the transactivation activity of ThNAC7, full length or truncated CDSs of ThNAC7 were constructed to pGBKT7 vector and transformed into Y2HGold cells to detect their transactivation activity (Figure 2B). All transformants could grow normally on the SD/-Trp plates, showing that they had been transformed in Y2HGold cells. The yeast cells containing the full-length CDS of ThNAC7 grew well and appeared blue on the SD/-Trp-His/X-a-Gal plates, suggesting that this protein is capable of transcriptional activation. Furthermore, we noticed that the yeast cells transformed with the assumed C-terminal activation domain (dc2, amino acids 146-578) of ThNAC7 thrived and became blue, whereas cells expressing the N-terminal domain (dc1, amino acid 1-435) of ThNAC7 could not grow, showing that the C-terminal of ThNAC7 has transactivation activity. The truncated CDSs expressing amino acids 146-290 and 291-435 retained the transactivation activity, whereas cells expressing the 436-578 fragment had completely abolished transactivation activity. Moreover, the smallest fragment of ThNAC7 that retained transactivation activity was located respectively in amino acids 216-290, 291-360, and 361-435. Taken together, the results indicated that ThNAC7 has transcriptional activation with three independent activation domains: aa 216-290, 291-360 and 361-435, respectively. 
A

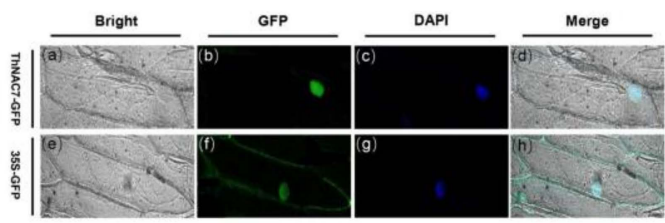

B
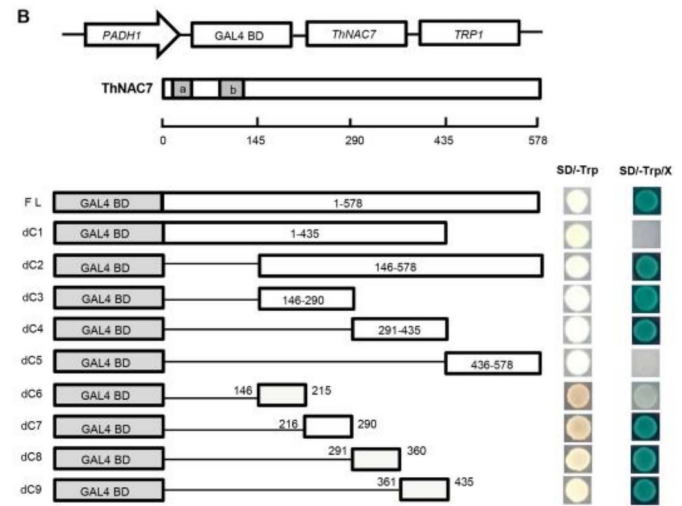

Figure 2. Subcellular localization and transcriptional activation of ThNAC7. (A): Subcellular localization analysis of ThNAC7. The onion nuclei were visualised through DAPI (4' ${ }^{\prime}$ 6-diamidino-2-phenylindole) staining. Bars, $50 \mu \mathrm{m}$. (B): Transactivation assay of ThNAC7 (a, b: NAC domain). A diagram of the pGBKT7 constructs for expressing different truncated ThNAC7 proteins in yeast cells. Transactivation assay of the intact or truncated ThNAC7 proteins. Full length or truncated CDSs of ThNAC7 were constructed into pGBKT7 vector and transformed into Y2HGold cells, and grown on SD/-Trp or $\mathrm{SD} /$-Trp/-His/X- $\alpha$-gal mediums to assess their transcriptional activation.

\subsection{The Expression of ThNAC7 Is Induced by Osmotic and Salt Stress}

QRT-PCR assay proved that the expression of ThNAC7 was markedly induced by osmotic ( $400 \mathrm{mM}$ mannitol) or salt $(300 \mathrm{mM} \mathrm{NaCl})$ stress in both roots and leaves of T. hispida (Figure 3). Under salt stress conditions, ThNAC7 was highly induced at $12 \mathrm{~h}$ in root tissue; meanwhile, it was highly induced at $24 \mathrm{~h}$ in leaf tissue (Figure 3A,B). Under osmotic stress conditions, ThNAC7 was highly induced at $12 \mathrm{~h}$ in leaf tissue and at $6 \mathrm{~h}$ in root tissue (Figure 3C,D). These results showed that the expression of ThNAC7 is induced by osmotic and salt stress, implying that $T h N A C 7$ plays roles in osmotic and salt stress responses. 
A

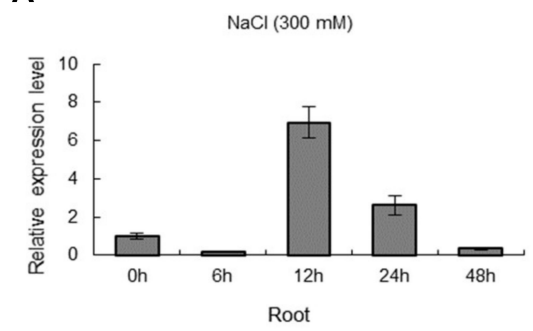

C

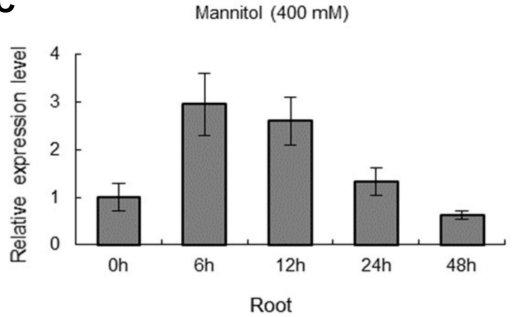

B

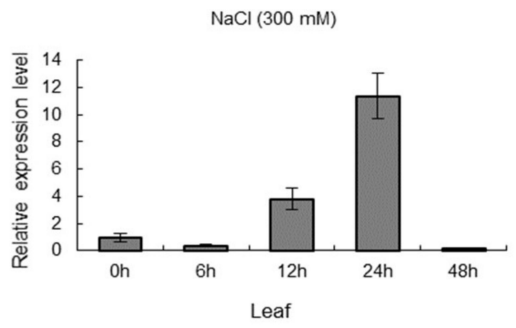

D

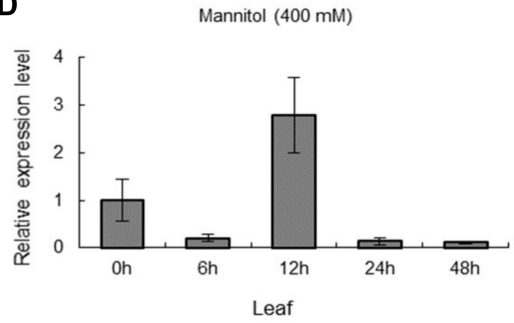

Figure 3. The expression level of ThNAC7 in response to osmotic or salt stress in T. hispida. The expression patterns of ThNAC7 in roots or leaves of T. hispida plants in response to treatment with $\mathrm{NaCl}(300 \mathrm{mM})$ $(\mathbf{A}, \mathbf{B})$ or mannitol $(400 \mathrm{mM})(\mathbf{C}, \mathbf{D})$. The expression of ThNAC7 in normal conditions $(0 \mathrm{~h})$ was designed as 1 to standardize the expression level of $T h N A C 7$ in salt or osmotic conditions.

\subsection{Overexpression of ThNAC7 in Arabidopsis Confers Osmotic and Salt Stress Tolerance}

Nine independent $T_{3}$ homozygous lines overexpressing ThNAC7 were obatined to verify the molecular function of ThNAC7 in salt and osmotic stress tolerance. RT-PCR and qRT-PCR results showed that the transgenic Arabidopsis successfully expressed the exogenous ThNAC7 (Figure S3). Moreover, the transcription of ThNAC7 in OE2 and OE5 lines was higher than that in other lines, so these two lines were chosen for further study (Figure S3C). In normal conditions, the OE2 and OE5 had no substantial distinction in growth phenotype compared to that of the Col-0 plants (control) (Figure 4A-C). However, OE2 and OE5 showed greatly enhanced root growth and fresh weight in osmotic or salt stress compared with those in the Col-0 (Figure 4A-C). Col-0 and transgenic Arabidopsis plants had approximately the same chlorophyll contents before treatment, whereas the OE2 and OE5 lines both had markedly higher chlorophyll contents than Col-0 plants in salt or osmotic stress (Figure 4D). In addition, phenotypic growth and fresh weight analyses of the plants growing in soil also indicated that OE2 and OE5 grew much better and had higher fresh weights than Col-0 plants (Figure 4E,F). The results suggested that ThNAC7 plays positive regulatory roles in the regulation of salt and osmotic stress. 
A
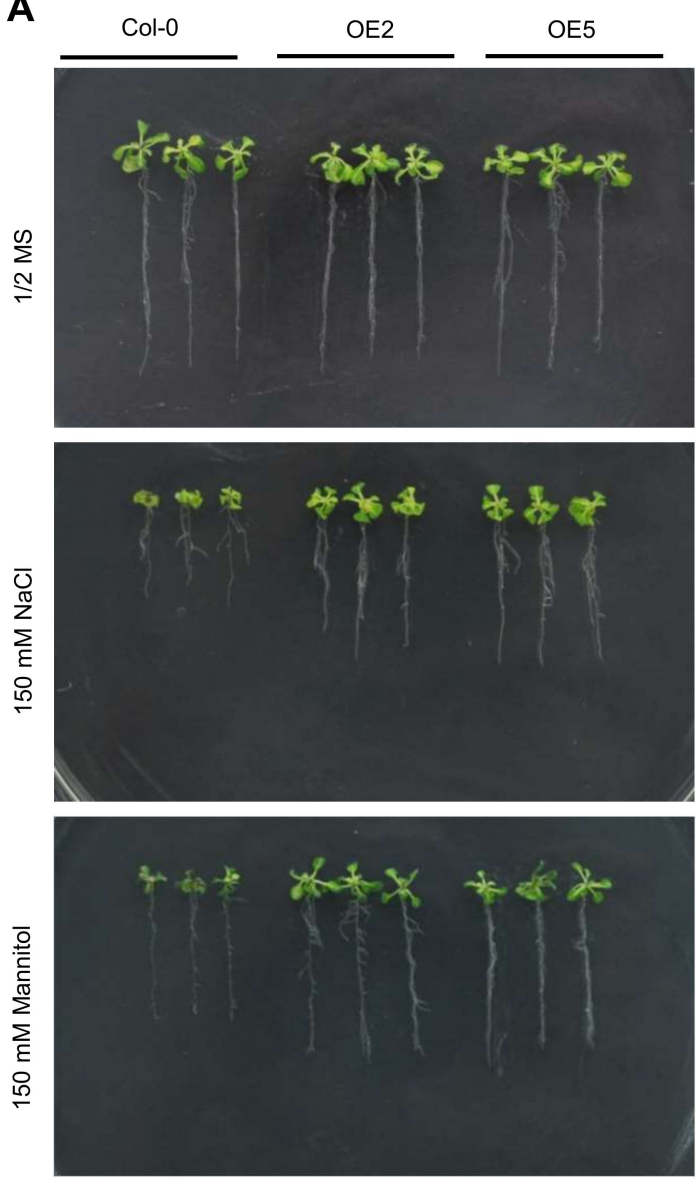

$\mathbf{E}$

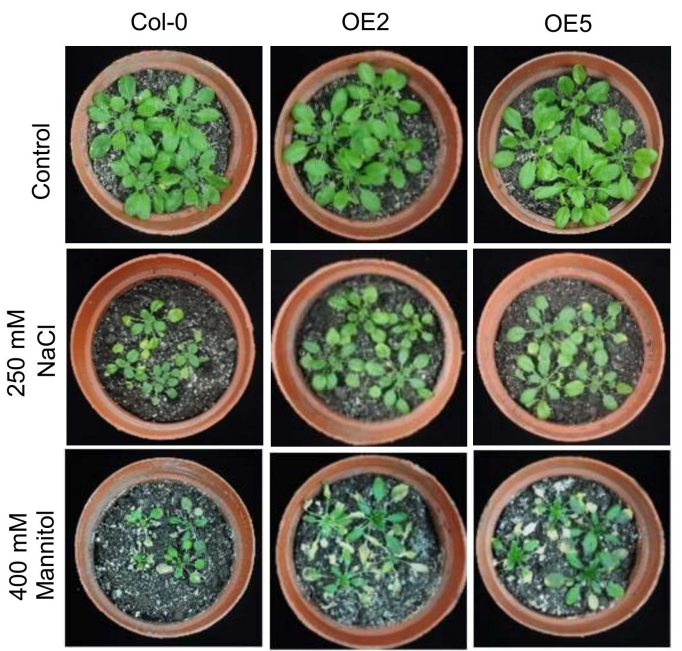

B

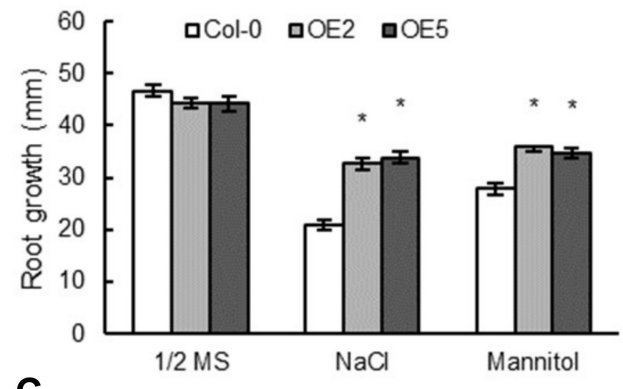

C

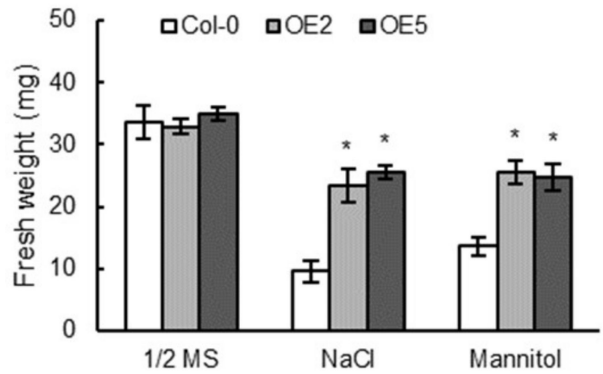

D

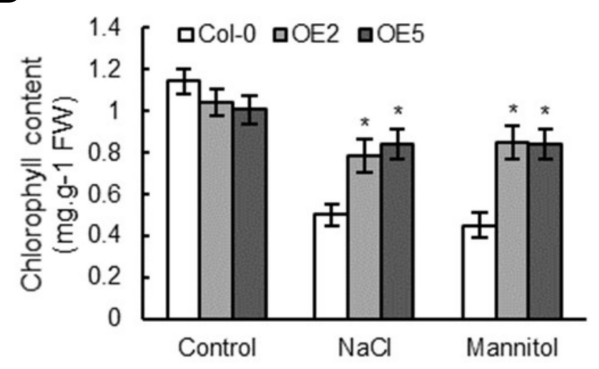

$\mathbf{F}$

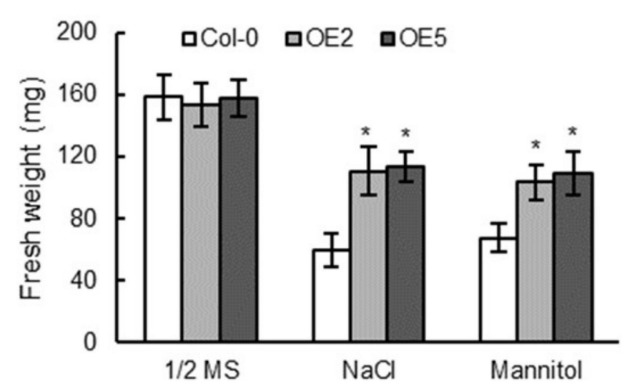

Figure 4. Stress tolerance of overexpressing ThNAC7 in Arabidopsis. (A): Growth phenotype of transgenic and Col-0 plants under normal (1/2 MS), salt (150 mM NaCl), or osmotic (150 mM mannitol) stress. (B): Root length assay. (C): Analysis of fresh weight. (D): Chlorophyll content assay. The plants were cultured in 1/2 MS (as control) or 1/2 MS containing $150 \mathrm{mM} \mathrm{NaCl}$ or $150 \mathrm{mM}$ mannitol for 14 days for the above analysis. (E): Growth phenotype of Arabidopsis plants. (F): Fresh weight of Arabidopsis seedlings. Three weeks old Arabidopsis seedlings in soil were treated with $400 \mathrm{mM}$ mannitol or $250 \mathrm{mM}$ $\mathrm{NaCl}$ for 2 weeks, then took a photograph of their phenotypes. Control: Plants growing in normal conditions. The asterisks $(p<0.05)$ show * significant differences compared to Col-0 Arabidopsis. Col-0: wild-type Arabidopsis plants; OE2 and 5: Arabidopsis lines 2 and 5 transformed with ThNAC7. 


\subsection{Transient Overexpression or Knockdown of ThNAC7 in T. hispida Plants}

To further study the role of ThNAC7 using gain- and loss- of function studies, we confirmed the expression level of ThNAC7 in overexpressing ThNAC7 (OE), RNAi-silenced ThNAC7 (IE), and control plants (transfected with pROKII) using qRT-PCR. We used the transcription level of ThNAC7 in plants transformed for 48 hours in control plants as the standard (designated as 1) to standardize the corresponding expression of ThNAC7 in the other T. hispida seedlings. The OE plants showed markedly enhanced levels of ThNAC7 transcripts, while they were dramatically reduced in the IE plants in comparison with those in the control T. hispida plants (Figure S4), which indicated that ThNAC7 had been successfully overexpressed or knocked down; therefore, these transgenic plants were suitable to study the gain- and loss-of-function of ThNAC7.

\subsection{The ROS Scavenging Capability Was Improved by Overexpressing ThNAC7}

Reactive oxygen species (ROS) accumulation is a substantial indicator to detect the degree of stress tolerance [26]. To determine ROS accumulation, two major ROS species, superoxide anion $\left(\mathrm{O}_{2}{ }^{-}\right)$ and hydrogen peroxide $\left(\mathrm{H}_{2} \mathrm{O}_{2}\right)$ were stained using nitroblue tetrazolium (NBT) and diaminobenzidine (DAB) in situ, respectively. Under salt and osmotic stress conditions, both NBT and DAB histochemical staining of T. hispida plants indicated that the OE T. hispida plants had the lowest levels of $\mathrm{O}_{2}{ }^{-}$and $\mathrm{H}_{2} \mathrm{O}_{2}$; while the IE had the highest levels (Figure 5A,B). Consistent with the DAB staining results, the determined content of $\mathrm{H}_{2} \mathrm{O}_{2}$ in the OE T. hispida plants was the lowest; and the IE T. hispida plants showed the highest $\mathrm{H}_{2} \mathrm{O}_{2}$ content in salt and osmotic stress environment (Figure $5 \mathrm{C}$ ). The above analyses were repeated in Arabidopsis. Under salt or osmotic stress environment, NBT and DAB histochemical staining and $\mathrm{H}_{2} \mathrm{O}_{2}$ content assay verified that ROS contents were markedly decreased in OE lines rather than in Col-0 plants (Figure S5A,B). SOD and POD activities, the two primary ROS scavenging enzymes, were further researched in T. hispida plants. In normal growth conditions, the POD and SOD activities of OE plants were not significantly different from those of IE and control plants (Figure 5D,E). However, under salt or osmotic stress environment, markedly higher activities of POD and SOD were detected in OE plants; while the IE plants had greatly lower POD and SOD activities compared to those in the control plants (Figure 5D,E). These analyses were repeated in Arabidopsis plants. The SOD and POD activity analysis showed that the OE plants had markedly enhanced the SOD and POD activities compared to those of the Col-0 Arabidopsis plants in osmotic and salt stress environment (Figure S5D,E). These results showed that ThNAC7 expression results in reduced ROS accumulation in plant cells, mediated by increased POD and SOD activities.

\subsection{The Expression Levels of SODs and PODs Are Induced by ThNAC7}

We further analysed the transcription levels of SODs and PODs to confirm whether overexpression of the SOD and POD genes could increase SOD and POD activities. We analyzed 3 ThSOD genes (GenBank numbers: KF756930-KF756932) and 3 ThPOD genes (GenBank numbers: KF756934-KF756936). The results indicated that compared to that in control T. hispida, the OE plants indicated markedly increased expression of all the analysed PODs and SODs in osmotic and salt stress environment, while their expression were markedly reduced in the IE plants (Figure 6). Three Arabidopsis PODs (AT2G18140, AT5G58400 and AT1G14550) and three Arabidopsis SOD genes (AT2G28190, AT3G10920 and AT1G08830) were assessed to test the expression patterns of them in Arabidopsis seedlings. Compared with the expression levels of the Col-0 plants, the SODs and PODs of all the studies were markedly advanced in transgenic lines in both salt and osmotic stress environments (Figure S6). The results showed that the expression of SODs and PODs could be induced by ThNAC7, which would result in enhanced SOD and POD enzyme activities. 
A

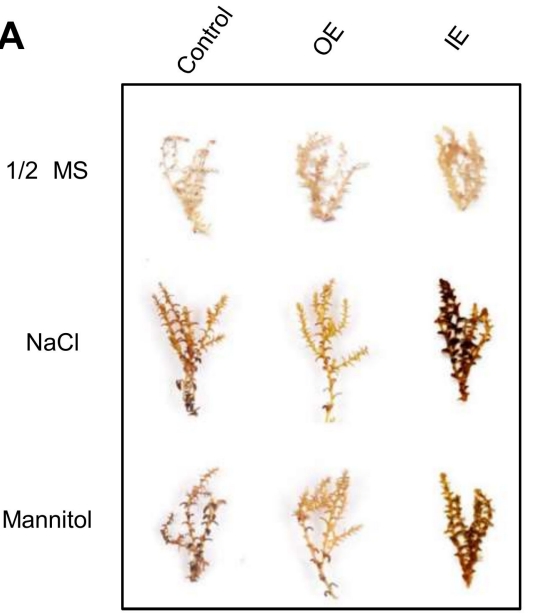

C

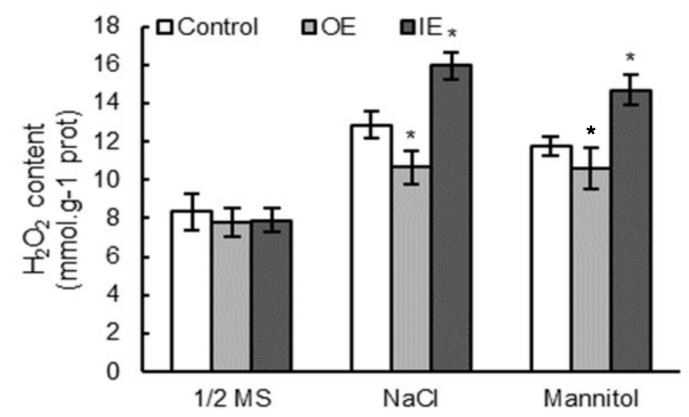

B

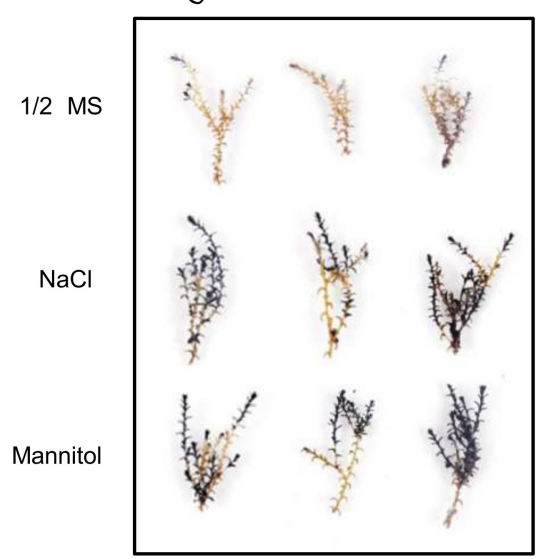

D

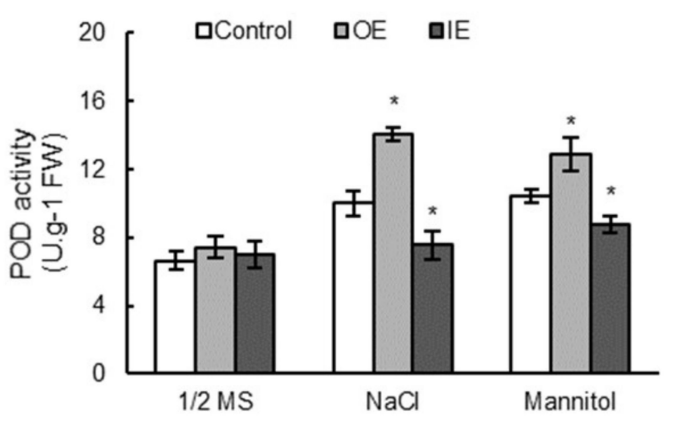

E

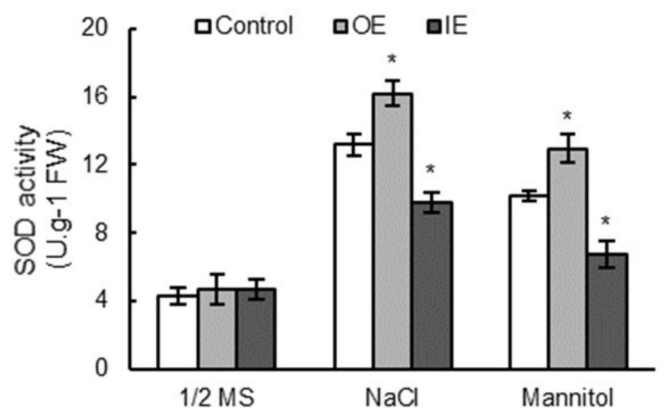

Figure 5. Analysis of ROS accumulation and the activities of SOD and POD among OE, IE, and control T. hispida plants. (A,B): T. hispida plants treated with $\mathrm{NaCl}(150 \mathrm{Mm})$ or mannitol $(200 \mathrm{mM})$, and stained with DAB to visualise $\mathrm{H}_{2} \mathrm{O}_{2}$ level (A), or stained with NBT to visualise $\mathrm{O}_{2}{ }^{-}$(B). (C): Measurement of $\mathrm{H}_{2} \mathrm{O}_{2}$ levels in T. hispida. (D,E): Measurement of the POD (D) and SOD (E) activity. OE: T. hispida plants overexpressing ThNAC7; IE: ThNAC7 RNAi-silenced T. hispida seedlings; Control: T. hispida plants transformed with pROKII. 

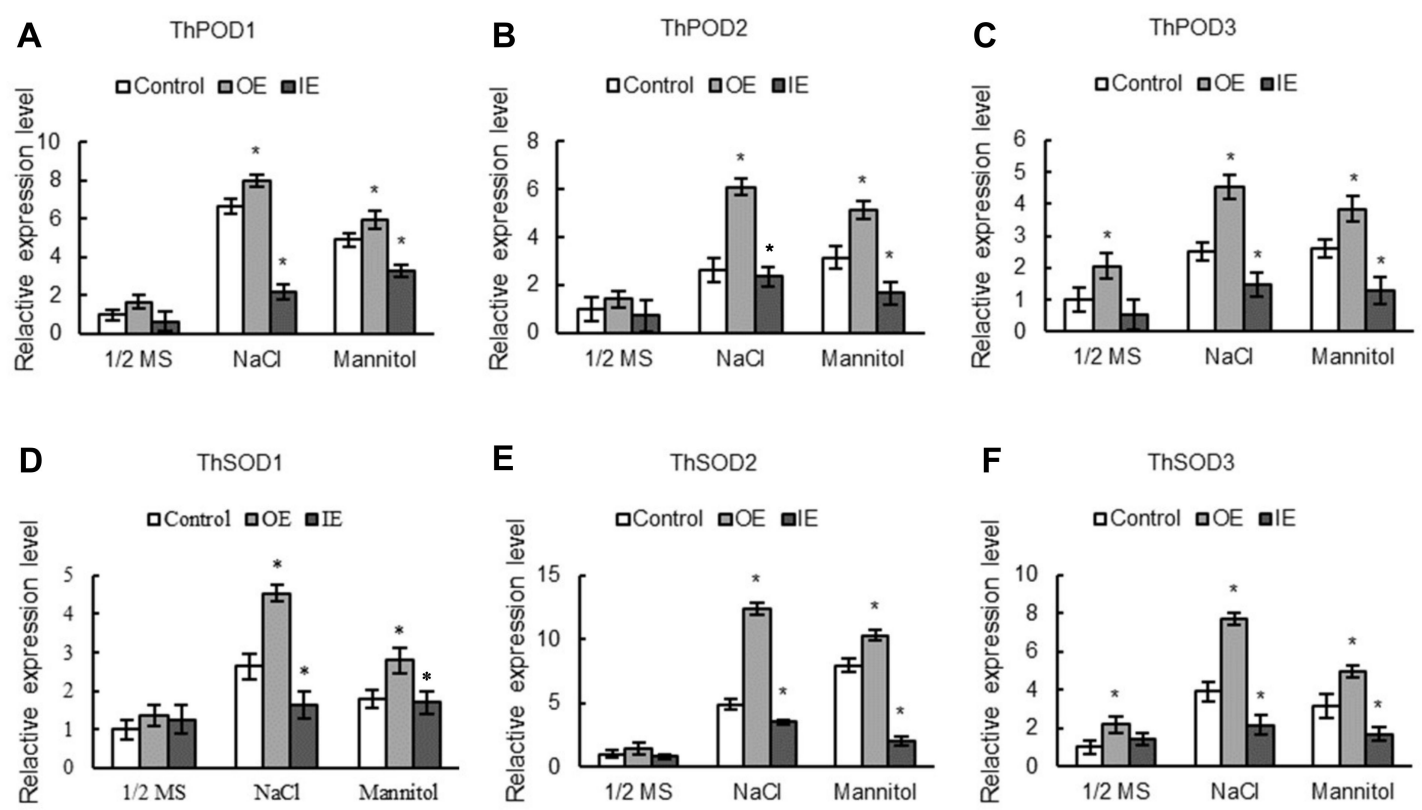

Figure 6. The expression patterns of the PODs and SODs in OE, IE, and control T. hispida seedlings. The expression of PODs (A) and SODs (B) were analyzed in control, OE, and IE T. hispida in response to salt $(150 \mathrm{mM} \mathrm{NaCl})$ or osmotic $(200 \mathrm{mM}$ mannitol) stress. The transcription level of a gene in control under normal growth conditions was designed as 1 to standardize its relative expression values. OE: T. hispida seedlings overexpressed ThNAC7; IE: ThNAC7 RNAi-silenced T. hispida seedlings; Control: T. hispida seedlings transformed with pROKII. * Significant $(p<0.05)$ difference compared to the control plants.

\subsection{Overexpression of ThNAC7 Reduces Water Loss Rate, Cell Death and Malondialdehyde Contents}

Electrolyte leakage is associated with plant stress response, and stress-induced electrolyte leakage is often associated with the accumulation of ROS, usually leading to PCD (programmed cell death) [28]. The electrolyte leakage rates were measured to monitor cell death in T. hispida under different environment. They had not substantial difference in electrolyte leakage rates of the OE, IE, and control T. hispida plants in normal growth conditions, while the electrolyte leakage rates showed marked differences under osmotic and salt stress environment. The highest electrolyte leakage rates appeared in the IE plants, then in the control, and the lowest in OE plants (Figure 7A). The water loss assay indicated that the water loss rates of OE plants were lower than those in the control, while that of IE plants were the highest (Figure 7B). Moreover, the MDA contents were similar among the control, OE, and IE T. hispida plants in normal growth environment. Nevertheless, the highest MDA level was appeared in the IE plants, followed by the control plants, and the lowest levels were recorded in the OE T. hispida plants in osmotic and salt stress (Figure 7C). In addition, the electrolyte leakage rate, MDA content and water loss rate in transgenic Arabidopsis seedlings were all markedly decreased compared to those in Col-0 Arabidopsis plants under osmotic and salt stress (Figure S7). The results were richly consistent with the results from the T. hispida seedlings, proving that overexpression of ThNAC7 could decrease the water loss rate, cell death, and MDA content in osmotic and salt stress environments to protect plants. 

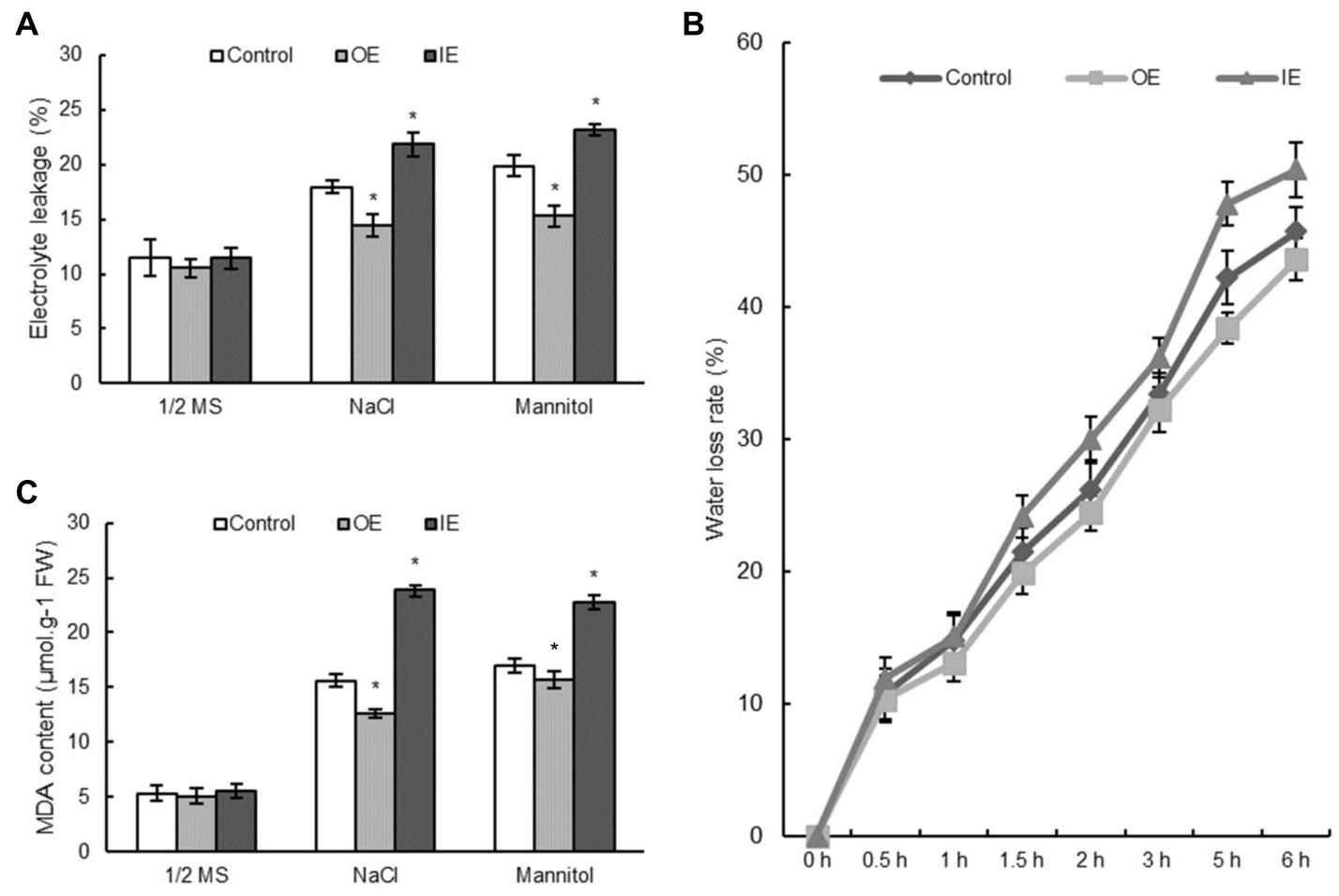

Figure 7. Detection of cell death, water loss rates, and MDA level in OE, IE, and control T. hispida seedlings. (A): Electrolyte leakage rates assay. (B): Water loss rates. (C): MDA content. The T. hispida plants were treated with $\mathrm{H}_{2} \mathrm{O}$ (as control), $\mathrm{NaCl}(150 \mathrm{mM})$, or mannitol $(200 \mathrm{mM})$ for $24 \mathrm{~h}$. Data are means \pm SD from 3 independent experiments. * Significant $(p<0.05)$ difference compared to the control. OE: T. hispida overexpressing ThNAC7; IE: ThNAC7 RNAi-silenced T. hispida; Control: T. hispida plants transformed with pROKII.

\subsection{ThNAC7 Positively Affects Proline Biosynthesis}

We next studied whether ThNAC7 is involved in proline biosynthesis in salt or osmotic stress environment. The proline contents were measured in comparison of the control, OE, and IE T. hispida seedlings. There was no difference in proline contents among the above three T. hispida seedlings in normal environment; whereas, there were substantial differences in the proline contents among the OE, IE, and control T. hispida plants in osmotic or salt stress. The order of the proline contents from highest to lowest was the OE plants, the control plants, and the IE T. hispida plants (Figure 8A). We further studied whether the altered proline contents were caused by changes in expression of proline biosynthesis genes, including ThP5CS genes (delta 1-pyrroline-5-carboxylate synthetase, GenBank number: KM101096 and KM101097). There was no difference in expression of ThP5CS1 and ThP5CS2 among all 3 types of plants in normal conditions. Under osmotic or salt stress, overexpression of ThNAC7 induced the transcription levels of proline biosynthesis related genes, including ThP5CS1 and ThP5CS2 (Figure 8B,C). 
A

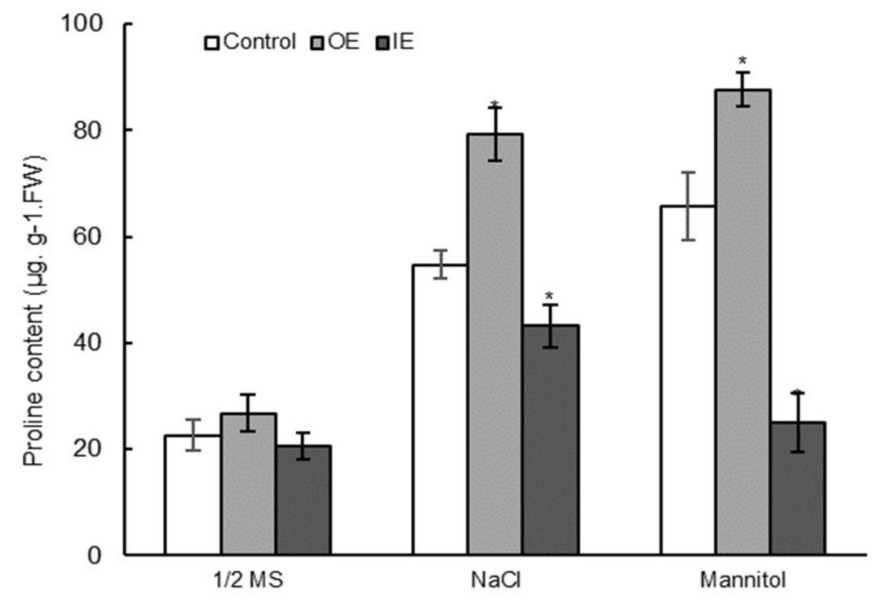

B

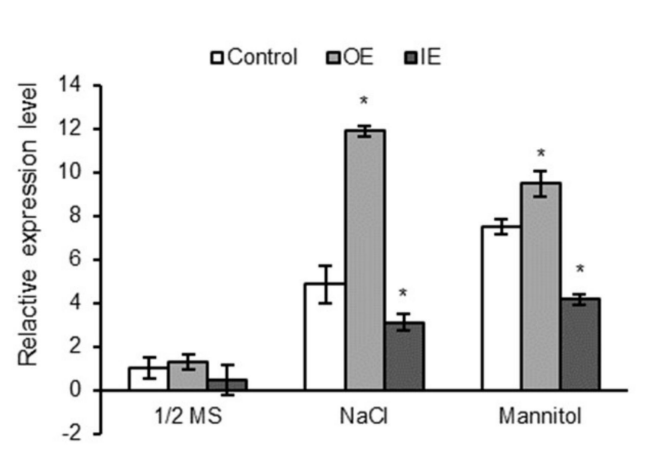

C

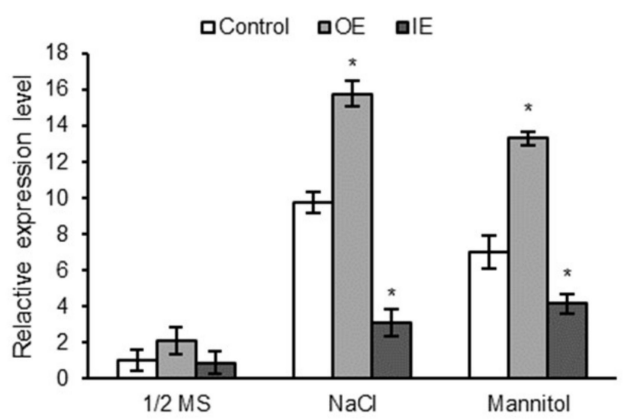

Figure 8. Analysis of the effect of ThNAC7 on the biosynthesis of proline. (A): Analysis of proline contents in OE, IE, and control T. hispida seedlings in response to osmotic (200 mM Mannitol) or salt (150 mM NaCl)stresses. (B,C): The expression levels of proline biosynthesis related genes. The relative expression levels were $\log 2$ transformed. Asterisk indicate significant $(p<0.05)$ difference compared to the control. OE: T. hispida plants overexpressing ThNAC7; IE: ThNAC7 RNAi-silenced T. hispida seedlings; Control: T. hispida plants transformed with pROKII.

To confirm the role of ThNAC7 in proline biosynthesis, we repeated the above analyses on Arabidopsis transformed with Col-0 and ThNAC7Arabidopsis plants. In normal growth environment, the Col-0 and OE plants had similar proline contents. By contrast, under salt or osmotic stress, the proline levels in OE2 and OE5 lines were markedly increased compared with the Col-0 (Figure S8A). We further studied the gene expression related to proline biosynthesis, i.e., AtP5CS1 (AT2G39800) and AtP5CS2 (AT3G55610). Under the salt or osmotic stress conditions, both AtP5CS1 and AtP5CS2 showed markedly higher expression in OE2 and OE5 lines than in Col-0 plants (Figure S8B,C). These outcomes are in accordance with the results in T. hispida.

\subsection{Identification of the Genes Regulated by ThNAC7 Using RNA-Seq}

The ThNAC7-overexpressing Arabidopsis plants displayed higher tolerance than Col-0 Arabidopsis plants in salt stress; therefore, we performed an RNA-seq analysis of OE5 and Col-0 to verify the down-stream target genes of ThNAC7 responsible for enhancing salt tolerance.

Under normal conditions, between OE5 and Col-0, a total of 272 differentially expressed genes (DEGs, $\log 2$ ratio $>1$, FDR < 0.05) were obtained, and 185 were upregulated and 87 were downregulated (Table S4). Total of 673 DEGs were obtained, including 453 that were induced by ThNAC7 and 220 that were inhibited by ThNAC7 under salt stress (Table S5). Among the DEGs upregulated under salt stress conditions with functional information, we found that over 40 encoded proteins and multiple TF genes that respond to salt stress (Table 1), such as peroxidase; lipid transfer protein; MAP kinase; 
late embryogenesis abundant protein; aquaporin; ethylene-responsive TF genes; and MYB, HSF, DREB, $T C P, N A C, b Z I P$, and WRKY TF genes.

Table 1. List of DEGs upregulated in response to salt stress in ThNAC7-overexpression line OE5 compared with Col-0 Arabidopsis plants.

\begin{tabular}{|c|c|c|c|c|}
\hline Locus ID & Gene Name & FDR & Fold Change & Annotations-Description \\
\hline AT5G42180 & PER64 & $2.62 \times 10^{-8}$ & 6.65 & peroxidase \\
\hline AT1G43160 & RAP2.6 & $6.88 \times 10^{-16}$ & 4.12 & $\begin{array}{l}\text { ethylene-responsive transcription } \\
\text { factor RAP2-6 }\end{array}$ \\
\hline AT1G09540 & MYB61 & $1.02 \times 10^{-6}$ & 3.44 & myb domain protein 61 \\
\hline AT5G64750 & ABR1 & $8.68 \times 10^{-20}$ & 3.04 & $\begin{array}{l}\text { ethylene-responsive transcription } \\
\text { factor ABR1 }\end{array}$ \\
\hline AT2G45180 & LTP & $1.23 \times 10^{-21}$ & 2.78 & $\begin{array}{l}\text { lipid transfer protein (LTP) family } \\
\text { protein }\end{array}$ \\
\hline AT2G32510 & MAPKКK17 & $5.09 \times 10^{-9}$ & 2.38 & $\begin{array}{l}\text { mitogen-activated protein kinase } \\
\text { kinasekinase } 17\end{array}$ \\
\hline AT1G52690 & LEA & 0.004977 & 2.31 & $\begin{array}{l}\text { Late embryogenesis abundant protein } \\
\text { (LEA) family protein }\end{array}$ \\
\hline AT1G21910 & DREB26 & $2.03 \times 10^{-6}$ & 2.24 & $\begin{array}{l}\text { ethylene-responsive transcription } \\
\text { factor ERF012 }\end{array}$ \\
\hline AT4G29930 & bHLH27 & $1.36 \times 10^{-7}$ & 2.2 & transcription factor bHLH27 \\
\hline AT1G05100 & MAPKKK18 & 0.008566 & 2.18 & $\begin{array}{l}\text { mitogen-activated protein kinase } \\
\text { kinasekinase } 18\end{array}$ \\
\hline AT4G22470 & LTP & $6.33 \times 10^{-10}$ & 2.12 & $\begin{array}{l}\text { lipid transfer protein (LTP) family } \\
\text { protein }\end{array}$ \\
\hline AT5G59310 & LTP4 & $1.96 \times 10^{-7}$ & 2.11 & non-specific lipid-transfer protein 4 \\
\hline AT2G37180 & RD28 & $6.49 \times 10^{-44}$ & 2.1 & aquaporin PIP2-3 \\
\hline AT5G12020 & HSP17.6II & 0.008487 & 2.1 & class II heat shock protein 17.6 \\
\hline AT2G20880 & ERF053 & 0.00016 & 2.09 & $\begin{array}{l}\text { ethylene-responsive transcription } \\
\text { factor ERF053 }\end{array}$ \\
\hline AT2G40340 & DREB2C & 0.000646 & 2.04 & $\begin{array}{l}\text { dehydration-responsive } \\
\text { element-binding protein } 2 \mathrm{C}\end{array}$ \\
\hline AT5G61890 & ERF114 & 0.001014 & 2.03 & $\begin{array}{l}\text { ethylene-responsive transcription } \\
\text { factor ERF114 }\end{array}$ \\
\hline AT4G05100 & AtMYB74 & $2.65 \times 10^{-7}$ & 2.01 & myb domain protein 74 \\
\hline AT3G18550 & BRC1 & 0.000907 & 1.93 & transcription factor TCP18 \\
\hline AT4G18170 & WRKY28 & $2.97 \times 10^{-7}$ & 1.75 & DNA binding-like protein \\
\hline AT5G13330 & RAP2.6L & $3.84 \times 10^{-12}$ & 1.71 & $\begin{array}{l}\text { ethylene-responsive transcription } \\
\text { factor ERF113 }\end{array}$ \\
\hline AT1G67260 & TCP1 & $2.94 \times 10^{-7}$ & 1.71 & transcription factor TCP1 \\
\hline AT1G71030 & ATMYBL2 & $2.28 \times 10^{-8}$ & 1.64 & $\begin{array}{l}\text { putative myb family transcription } \\
\text { factor }\end{array}$ \\
\hline AT5G39610 & ATNAC2 & $9.09 \times 10^{-6}$ & 1.63 & NAC-domain transcription factor \\
\hline AT2G22200 & ERF056 & $4.68 \times 10^{-5}$ & 1.63 & $\begin{array}{l}\text { ethylene-responsive transcription } \\
\text { factor ERF056 }\end{array}$ \\
\hline AT1G75490 & DREB2D & 0.001527 & 1.6 & $\begin{array}{l}\text { dehydration-responsive } \\
\text { element-binding protein 2D }\end{array}$ \\
\hline AT4G23400 & PIP1D & $3.65 \times 10^{-11}$ & 1.57 & putative aquaporin PIP1-5 \\
\hline AT5G40630 & - & 0.001874 & 1.56 & ubiquitin family protein \\
\hline AT2G22770 & bHLH020 & $6.89 \times 10^{-6}$ & 1.44 & putative bHLH transcription factor \\
\hline AT2G26150 & ATHSFA2 & $2.19 \times 10^{-6}$ & 1.43 & heat stress transcription factor A-2 \\
\hline AT3G53420 & PIP2A & $1.95 \times 10^{-13}$ & 1.4 & aquaporin PIP2-1 \\
\hline AT5G56550 & OXS3 & $1.04 \times 10^{-10}$ & 1.37 & protein OXIDATIVE STRESS 3 \\
\hline AT2G21650 & MEE3 & 0.006908 & 1.36 & MYB transcription factor RSM1 \\
\hline AT4G27410 & RD26 & $6.73 \times 10^{-5}$ & 1.33 & NAC transcription factor RD26 \\
\hline AT5G60890 & ATMYB34 & $1.14 \times 10^{-7}$ & 1.31 & myb domain protein 34 \\
\hline AT1G56650 & PAP1 & $2.41 \times 10^{-5}$ & 1.28 & transcription factor MYB75 \\
\hline AT1G54100 & ALDH7B4 & $1.61 \times 10^{-8}$ & 1.28 & aldehyde dehydrogenase 7B4 \\
\hline AT5G28770 & ATbZIP63 & $1.08 \times 10^{-13}$ & 1.27 & basic leucine zipper 63 \\
\hline AT5G50915 & bHLH137 & $3.16 \times 10^{-5}$ & 1.21 & transcription factor bHLH137 \\
\hline AT2G36830 & TIP & $2.04 \times 10^{-10}$ & 1.21 & aquaporin TIP1-1 \\
\hline
\end{tabular}

GO (Gene ontology) analyses showed that these DEGs were primarily related to 1 molecular function, 12 biological processes and three cellular components. Most were categorized in "metabolic 
process", "single-organism process", "cell part", "cell", and "organelle". The other genes were assigned to "cell process", "response to stimulus", "biological regulation", "cellular component organization or biogenesis", "localization", "development process", "signaling", "reproductive process", "multicellular organismal process", "reproduction", "binding", and "catalytic activity" (Figure S9).

Furthermore, we randomly selected 12 DEGs related to salt stress (six upregulated and six downregulated) and compared their expression levels between Col-0 and OE5 Arabidopsis plants by qRT-PCR (Table 2 and Table S6). As shown in Figure 9 and Figure S10, all these genes had similar expression patterns to those decided using RNA-seq, proving the reliability of the RNA-seq results.

Table 2. The expression values of RNA-seq for validation of the selected DEGs.

\begin{tabular}{cccc}
\hline Locus ID & FDR & Fold Change & Annotations-Description \\
\hline AT5G42180 & $2.62 \times 10^{-8}$ & 6.65 & peroxidase \\
AT5G24240 & 0.01 & 4.44 & phosphatidylinositol 3- and 4-kinase/ubiquitin family protein \\
AT5G57550 & $3.65 \times 10^{-20}$ & 4.35 & probable xyloglucan endotransglucosylase/hydrolase protein 25 \\
AT1G75750 & $3.37 \times 10^{-38}$ & 4.26 & GA-responsive GAST1 protein-like protein \\
AT2G38240 & $2.86 \times 10^{-13}$ & 4.21 & 2-oxoglutarate (2OG) and Fe (II)-dependent oxygenase-like protein \\
AT1G43160 & $6.88 \times 10^{-16}$ & 4.12 & ethylene-responsive transcription factor RAP2-6 \\
AT4G22485 & $5.48 \times 10^{-4}$ & -4.81 & protease inhibitor/seed storage/LTP family protein \\
AT2G34390 & $6.8 \times 10^{-14}$ & -4.7 & aquaporin NIP2-1 \\
AT1G50750 & $5.5 \times 10^{-9}$ & -3.71 & plant mobile domain family protein \\
AT2G26010 & $1.24 \times 10^{-5}$ & -3.07 & plant defensin 1.3 \\
AT4G29610 & $2.42 \times 10^{-14}$ & -2.73 & -1.36 \\
AT5G52750 & $2.14 \times 10^{-8}$ & & cytidine/deoxycytidylate deaminase family protein \\
\end{tabular}



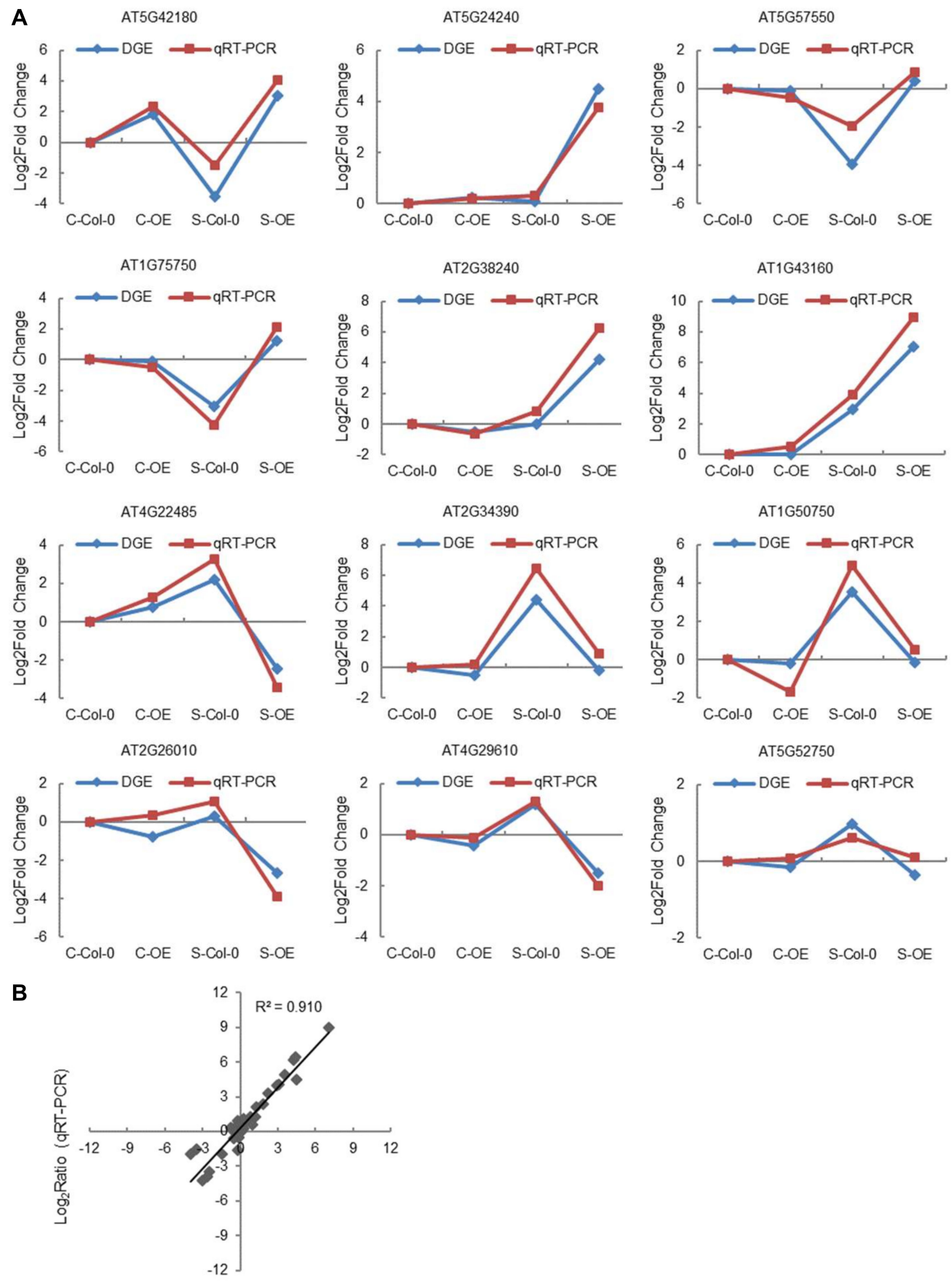

$\log _{2}$ Ratio (DGE)

Figure 9. Comparison of the expression patterns between RNA-seq and qRT-PCR. A: Twelve highly differentially regulated genes were randomly selected for qRT-PCR assay. B: Correlation: correlation analysis of the results between qRT-PCR and RNA-sequencing; the correlation coefficient $\mathrm{R}^{2}$ is 0.910 . * Significant $(p<0.05)$ difference compared with the control plants.

\section{Discussion}

Previously, we identified 16 NAC TFs that are involved in the differential response to $\mathrm{NaHCO}_{3}$ stress [27]. Furthermore, we confirmed that ThNAC7 was greatly induced by salt stress; therefore, we selected ThNAC7 for further research. Transactivation assays indicated that ThNAC7 has 
transcriptional activation that lies within three independent activation domains: aa 216-290, 291-360, and 361-435, respectively (Figure 2B). The full-length ThNAC7 protein showed strong transcriptional activation activity without the N-terminal domain (dc1, 1-435), containing three activation domains, abolished the transcriptional activation activity. These results indicated that ThNAC7 might possess a transcriptional repression domain in N-terminal 1-145 amino acids. The transactivation activity of NAC TFs might depend upon the interaction between the NAC activation domain and repression domain [29]. Therefore, whether ThNAC7 is a transcriptional activator or repressor depends on its interactions with other TFs or target genes.

The expression of ThNAC7 was greatly induced by osmotic or salt stress conditions in T. hispida (Figure 3), indicating that ThNAC7 plays roles in abiotic stress responses. To analyze the molecular function of ThNAC7 in resistance to abiotic stress, two independent ThNAC7 transgenic lines (OE2 and OE5) lines were used in further study. The overexpression of ThNAC7 in transgenic Arabidopsis improved root growth (Figure 4A,B), fresh weight (Figure 4C), and chlorophyll contents (Figure 4D). Therefore, ThNAC7 plays a positive role in osmotic or salt stress tolerance in plants.

ROS scavenging is crucial in resistance to plant abiotic stress [30-33]. We found that overexpression of ThNAC7 could reduce excess ROS accumulation in this study (Figure 5 and Figure S5), indicating that ThNAC7 is related to ROS scavenging. In addition, ThNAC7 can induce the transcription levels of PODs and SODs in transiently transformed T. hispida and stably transformed Arabidopsis (Figure 6 and Figure S6), thereby improving their activities (Figure 6 and Figure S6). Additionally, overexpression of ThNAC7 could decrease cell death, water loss rate, and the MDA content in osmotic or salt stress (Figure 7 and Figure S7). These data showed that ThNAC7 could elevate the transcription levels of ROS scavenging genes for improving stress tolerance. NAC TFs could enhance stress tolerance and modulate the expression level of ROS scavenging genes, which is accordance with previous studies [34-37]. Overexpression of ThNAC13 enhanced the osmotic and salt stress tolerances via controlling the transcriptional levels of PODs and SODs to enhance the ROS scavenging ability [34]. In this study, we found that both ThNAC7 and ThNAC13 belong to NAC subfamily I in T. hispida (Figure S2).

Proline is not only an osmotic agent, but also a radical scavenger. It can maintain photosynthetic activity and defend cells from harm in abiotic stress environments, allowing plants to maintain stable growing conditions under long term stress [38,39]. We found that the transcription levels of P5CSs were induced by ThNAC7 in T. hispida (Figure 8) and Arabidopsis (Figure S8). In addition, the transcription levels of P5CSs were positively related to the proline content (Figure 8). This result demonstrated that ThNAC7 activates proline biosynthesis to increase the proline content, which consequently increases abiotic stress tolerance by elevating the osmotic potential and ROS scavenging ability.

The RNA-seq analyses revealed that more than 40 upregulated genes are related to salt stress, including four aquaporins (AQPs) and three lipid transfer proteins LTPs (Table 1). Many AQPs in the PIP subfamilies affect the expression levels of mRNA transcripts or/and proteins under salt, drought, or cold stresses [40]. In transgenic Arabidopsis, the overexpression of OsPIP1 and OsPIP2 improved drought and salt tolerance [41]. LTPs are responsive to many abiotic stresses [42-44]. These results suggested that ThNAC7 might improve abiotic stress tolerance via inducing the transcription levels of $A Q P S$ and LTPS.

In addition, ThNAC7 regulated multiple TFs involved in abiotic stress. Seven ERFs were up-regulated by ThNAC7 in salt conditions. For instance, RAP2.6 can response to high cold, salt, osmotic and ABA stresses [45]. Overexpression of RAP2.6L in Arabidopsis had no impact on phenotype, but it could improve drought and salt stresses tolerance [46]. The $A B R 1$ gene could response to drought, salt, cold and ABA stresses [47]. Therefore, the ERF TFs mediated by ThNAC7 might play a vital role in salt stress tolerance. Moreover, other TF families were differentially expressed, such as MYB, bHLH, HSP, DREB, TCP, NAC, bZIP, and WRKY. Arabidopsis DREB2C plays vital roles in salt stress tolerance and the regulating of several genes related to abiotic stress [48]. The co-expression of AtWRKY28 and AtbHLH17 enhances resistance to $\mathrm{NaCl}$, Mannitol, and oxidative stress in Arabidopsis [49]. ATNAC2 and ANAC092 
are highly affected by salinity and can positively regulate the leaf senescence [50]. These results suggested that ThNAC7 may directly or indirectly regulate these stress-related TFs to improve salt stress resistance in plants.

\section{Materials and Methods}

\subsection{Plant Materials and Growth Conditions}

Seeds of T. hispida were planted in containers with a mixture of turf peat and sand (3:1 $v / v)$, were grown in the greenhouse maintained at $24{ }^{\circ} \mathrm{C}$, with $70-75 \%$ relative humidity and a $14 \mathrm{~h} \mathrm{light} / 10 \mathrm{~h}$ dark photocycle. Seeds of Arabidopsis thaliana Columbia (Col-0) were directly seeded into containers with a mixture of perlite and soil $(2: 1 \mathrm{v} / \mathrm{v})$ in the greenhouse at $22{ }^{\circ} \mathrm{C}$, with $65-70 \%$ relative humidity and a $16 \mathrm{~h}$ light $/ 8 \mathrm{~h}$ dark photocycle.

\subsection{Plasmid Construction and Plant Transformation}

In our previous study, eight transcriptomes were obtained from T. hispida [27]. The open reading frame (ORF) sequence of ThNAC7 (GenBank number: JQ974961) was obtained using the transcriptome data. Multiple sequence alignments of ThNAC7 and 10 NAC proteins from different species were performed using ClustalW. The NAC proteins of Arabidopsis were obtained from UniPort (http://www.uniport.org/). Phylogenetic tree analysis was generated between ThNAC7 and 105 NAC proteins from Arabidopsis using the MEGA6.06 program (Tokyo Metropolitan University and 1 Research Center for Genomics and Bioinformatics, Tokyo, Japan). Another phylogenetic tree was generated using MEGA6.06 between ThNAC7 and 88 NAC proteins from T. hispida.

The ORF of ThNAC7 was inserted into plasmid pROKII following the CaMV 355 promoter. The inverted repeat cDNA sequence of ThNAC7 was cloned to the pFGC5941 RNAi vector (pFGC::ThNAC7) to knockdown the expression of ThNAC7. All the primers used in the experiments are listed in Table S1. The highly efficient transient transformation of T. hispida plants were performed as previously described by Ji et al. [51]. We constructed three kinds of transgenic T. hispida plants: OE (overexpression) plants (transformed with 35S::ThNAC7), IE (inhibited expression) plants (transformed with pFGC::ThNAC7), and control T. hispida plants with the empty pROKII plasmid. The 35S::ThNAC7 plasmid was stably transformed into Arabidopsis by the Agrobacterium mediated floral dip transformation method to obtain ThNAC7 overexpressed plants [52]. $T_{3}$ homozygous transgenic Arabidopsis were used in further study.

\subsection{Subcellular Location of ThNAC7 Proteins}

The coding sequence (CDS) of ThNAC7 with no termination codon was fused with the C-terminus of the GFP following the CaMV 35S promoter. 35S::GFP was used as control. All primer used are listed in Table S1. The 35S::ThNAC7-GFP and 35S::GFP plasmids was respectively imported into onion epidermal cells by particle bombardment (Bio-Rad, Hercules, CA, USA). The nuclei were stained using $4^{\prime}$,6-diamidino-2-phenylindole (DAPI) $\left(10 \mu \mathrm{g} \cdot \mathrm{mL}^{-1}\right)$ with phosphate buffered saline for $5 \mathrm{~min}$. The transformed onion epidermal cells were visualised by LSM700 confocal laser scanning microscopy (Zeiss, Jena, Germany).

\subsection{Transactivational Activity of ThNAC7}

To evaluate the transcriptional activity of ThNAC7 and determine its transactivation domain, the full length or various truncated ThNAC7 fragments were fused to the yeast GAL4 DNA binding domain of the pGBKT7 (Clontech, Palo Alto, CA, USA) using Infusion enzyme (Clontech) and transformed in Y2HGold cells. The procedure was performed according to the Matchmaker ${ }^{\mathrm{TM}}$ Gold Yeast Two-Hybrid System instructions. In the transactivation assay, the transformed yeast cells were grown on SD/-Trp-His/X- $\alpha$-gal medium for 3-5 days. All primers were listed in Table S2. Three independent experiments were performed. 


\subsection{Stress Tolerance Assays}

The $\mathrm{T}_{3}$ generation ThNAC7 transgenic Arabidopsis lines were used as the materials for stress tolerance analyses. After culturing in 1/2 MS medium for 5 days, the germinated Arabidopsis seeds were separately transferred to $1 / 2 \mathrm{MS}$ or $1 / 2 \mathrm{MS}$ containing $150 \mathrm{mM}$ mannitol or $150 \mathrm{mM} \mathrm{NaCl}$ for two weeks. The fresh weight and root length of Arabidopsis were determined. The chlorophyll contents of excised leaves were measured as described by Lichtenthaler [53]. Arabidopsis seeds cultured in 1/2 MS plates for five days were planted in soil. The three-week seedlings were watered using $400 \mathrm{mM}$ mannitol or $250 \mathrm{mM} \mathrm{NaCl}$ for 2 weeks; the fresh weights of plants were also determined. Three independent experiments were performed.

\subsection{Physiological Measurements}

T. hispida seedlings were cultured in $1 / 2 \mathrm{MS}$ or $1 / 2 \mathrm{MS}$ with $200 \mathrm{mM}$ mannitol or $150 \mathrm{mM} \mathrm{NaCl}$ for 24 hours were for physiological assays. Arabidopsis grown into soil for 3 weeks were watered with $200 \mathrm{mM}$ mannitol or $150 \mathrm{mM}$ salt $(\mathrm{NaCl})$ solution at $24 \mathrm{~h}$ for physiological assay. The seedlings were treated with $200 \mathrm{mM}$ mannitol or $150 \mathrm{mM} \mathrm{NaCl}$ solution for 2 hours. The leaves of T. hispida or Arabidopsis plants was stained by nitroblue tetrazolium (NBT) and diaminobenzidine (DAB) using the methods of Fryer et al. [54,55]. The SOD and POD activities, and the MDA content were determined using the methods of Wang et al. [56]. The $\mathrm{H}_{2} \mathrm{O}_{2}$ level was detected according to the method of Dal Santo et al. [57]. An electrolyte leakage assay was determined via the method of Ji et al. [51]. The water loss rate was measured using the method of Zhang et al. [55]. The proline content was determined according to the method of Bates et al. [58]. Three independent experiments were performed.

\section{7. qRT-PCR Assay}

The total RNA of T. hispida was obtained using the Universal Plant Total RNA Extraction Kit (BioTeke). Arabidopsis total RNA was isolated using the Trizol reagent (Invitrogen, Waltham, MA, USA). Then RNA $(2 \mu \mathrm{g})$ was reversely transcribed into cDNA as PCR templates. Actin (GenBank number: FJ618517) and $\beta$-tubulin (GenBank number: FJ618519) were used as reference genes for T. hispida analysis (Table S3). For Arabidopsis analysis, $\alpha$-tubulin (AT1G50010) and Actin3 (AT3G53750) were used as reference genes (Table S3). The reaction system included $2 \mu \mathrm{L}$ of cDNA template, $0.5 \mu \mathrm{M}$ each of primer, and $10 \mu \mathrm{L}$ of SYBR Green Real time PCR Master Mix (Toyobo) in the volume of $20 \mu \mathrm{L}$. The procedure involved the following: $94{ }^{\circ} \mathrm{C} / 30 \mathrm{~s}$; followed by 45 cycles at $94{ }^{\circ} \mathrm{C} / 12 \mathrm{~s}, 60^{\circ} \mathrm{C} / 30 \mathrm{~s}$, and $72{ }^{\circ} \mathrm{C} / 40 \mathrm{~s}$; followed by $1 \mathrm{~s}$ at $82{ }^{\circ} \mathrm{C}$ for plate reading. The qRT-PCR was performed using an Opticon 2 System (Bio-Rad, Hercules, CA, USA). For each sample, the melting curve evaluated the purity of the PCR products. The expression levels of genes were treated using the $2^{-\Delta \Delta C t}$ method [59]. Three independent experiments were performed.

\subsection{RNA-Sequencing Analysis}

Total RNA from four-week-old ThNAC7-overexpression line OE5 and Col-0 Arabidopsis, without treatment or treated with $\mathrm{NaCl}(150 \mathrm{mM})$ for 6 hours, were used for RNA-sequencing, and three biological replicates were performed. Total RNAs were extracted using the Trizol reagent, and purified using AMPure beads (Agencourt, CA, USA). The preparation of the sequencing library and PCR amplification used a TruSeq PE Cluster Kit and a TruSeq ${ }^{\text {TM }}$ DNA Sample Prep Kit-Set A, respectively (Illumina, San Diego, CA, USA). RNA-seq was analyzed on the Illumina HiSeq 2000 platform. The relative expression levels were obtained under salt and normal conditions. All the relative expression levels were calculated using $\log _{2}$. With a log-fold expression change of $\left|\log _{2} \mathrm{FC}\right|$ $\geq 1$, and the threshold of false discovery rate (FDR $<0.05$ ), DEGs were identified via the DEGSeq algorithm [60]. The correlation between qRT-PCR and digital genes expression (DGE) was evaluated statistically by calculating the Pearson correlation coefficient. Gene ontology (GO) classification was 
executed using the molecule annotation system (MAS). The RNA-seq data was uploaded to the NCBI (PRJNA525176).

\subsection{Statistical Analyses}

Statistical analyses were accomplished with SPSS (IBM SPSS 22, IBM Corp., Armonk, NY, USA). Data were calculated using student's $t$-test. $p<0.05$ was statistically significant. * represents $p<0.05$ in the figures. Three biological replicates were carried out for statistical analyses.

\section{Conclusions}

A NAC TF from Tamarix hispida, ThNAC7, is a nuclear localization protein with transactivation activity. Overexpression of ThNAC7 markedly increased proline levels and enhanced the POD and SOD activities to increase the ROS scavenging ability in both transiently transformed T. hispida and stably transformed Arabidopsis. ThNAC7 positively regulated a series of genes that enhance osmotic and salt stress tolerance, including salt tolerance genes and many TF genes. Taken together, ThNAC7 promotes the expression level of genes related to stress tolerance in order to enhance osmotic and salt stress tolerance by improving the osmotic potential and increasing ROS scavenging. The results of the present study enrich the molecular mechanism of ThNAC7 involved in salt and osmotic stresses.

Supplementary Materials: The following are available online at http://www.mdpi.com/2223-7747/8/7/221/s1. Figure S1. Multiple sequence alignment analysis of NAC proteins from 10 other species. ThNAC7: Tamarix hispida (AFN55267.2); PpNAC17: Prunus persica (XP_007201176.1); PaNAC17: Prunus avium (XP_021820479.1); JrNAC17: Juglans regia (XP_018848079.1); MeNAC17: Manihot esculenta (XP_021603416.1); JcNAC17: Jatropha curcas (XP_012073984.1); NaNAC17: Nicotiana attenuate (XP_019238422.1); NtNAC17: Nicotiana tabacum (XP_016438196.1); PtNAC17: Populus trichocarpa (AOF43232.1); NnNAC17: Nelumbo nucifera (XP_010243336.1); and ANAC91: Arabidopsis (AT5G24590.1). Figure S2. Phylogenetic analysis between ThNAC7 and the NAC proteins from T. hispida. The phylogenetic relationship of ThNAC7 and the NAC proteins from the transcriptome of T. hispida. The amino acid sequences of ThNAC7 and $88 \mathrm{~T}$. hispida NAC proteins were aligned; the un-rooted NJ tree was constructed using MEGA 6.06. Figure S3. RT-PCR and qRT-PCR analysis of the expression level of exogenous ThNAC7 in transgenic Arabidopsis lines. Col-0: wild-type Arabidopsis plants; OE1-9: Arabidopsis lines transformed with ThNAC7, M: DL2000 marker. Figure S4. Expression of ThNAC7 in OE, IE and control T. hispida plants. T. hispida were cultured in 1/2 MS (normal conditions) or $1 / 2 \mathrm{MS}$ medium containing $150 \mathrm{mM} \mathrm{NaCl}$ or $200 \mathrm{mM}$ mannitol for $24 \mathrm{~h}$ to determine the expression level of ThNAC7. The expression level of ThNAC7 after $48 \mathrm{~h}$ of transformation in the control plants was regarded as a calibrator (designated as 1) to standardize the expression of ThNAC7 in the other plants. Control: T. hispida plants transformed with empty pROKII; OE: T. hispida plants overexpressing ThNAC7; IE: ThNAC7 RNAi-silenced plants. Asterisks indicate * significant $(p<0.05)$ difference compared with the control plants. Figure S5. Analysis of ROS accumulation and the activities of POD and SOD in OE and Col-0 Arabidopsis plants. A, B: Arabidopsis plants treated with $150 \mathrm{mM} \mathrm{NaCl}$ or $200 \mathrm{mM}$ mannitol, and stained with DAB to visualize $\mathrm{H} 2 \mathrm{O} 2$ (A), or stained with NBT to visualize O2- (B). C: Measurement of $\mathrm{H} 2 \mathrm{O} 2$ levels in Arabidopsis plants. D, E: Measurement of POD (D) and SOD (E) activities. Col-0: wild-type Arabidopsis plants; OE2 and 5: Arabidopsis lines 2 and 5 transformed with ThNAC7. Figure S6. The expression of the PODs and SODs in OE and Col-0 Arabidopsis plants. Analysis of POD (A) and SOD (B) gene expression was carried out in Arabidopsis OE and Col-0 plants in response to $\mathrm{NaCl}(150 \mathrm{mM})$ or Mannitol $(200 \mathrm{mM})$ stress treatments. The expression levels of the genes in Col-0 plants grown in the normal condition were regarded as a calibrator (designed as 1) to standardize the relative transcript values. Col-0: wild-type Arabidopsis plants; OE2, 5: the Arabidopsis lines transformed with ThNAC7. Figure S7. Detection of cell death, water loss rates, and MDA content in $\mathrm{OE}$ and Col-0 Arabidopsis plants. A: Comparison of electrolyte leakage rates. B: Water loss rates. C: MDA content. The plants were treated with water (control), $150 \mathrm{mM} \mathrm{NaCl}(\mathrm{NaCl})$, or $200 \mathrm{mM}$ Mannitol for $24 \mathrm{~h}$ for analyses. Data are means \pm SD from three independent experiments. * Significant $(p<0.05)$ difference compared with Col-0 plants. Col-0: wild-type Arabidopsis plants; OE2 and 5: lines 2 and 5 of Arabidopsis transformed with ThNAC7. Figure S8. Analysis of the biosynthesis of proline in OE and Col-0 Arabidopsis plants. A: Analysis of proline levels in OE and Col-0 plants in response to $\mathrm{NaCl}(150 \mathrm{mM})$ or Mannitol $(200 \mathrm{mM})$ stress treatments. B, C: The expression of proline biosynthesis and degradation-related genes. The relative expression levels were $\log 2$ transformed. * Significant $(p<0.05)$ difference compared with Col-0 plants. Col-0: wild-type Arabidopsis plants; OE2, 5: the Arabidopsis lines transformed with ThNAC7. Figure S9. GO classification of the annotated DEGs in salt stress. Figure S10. Comparison of the expression profiles between RNA-seq and qRT-PCR. Table S1. Primer sequences used to construct recombinant plasmids. Table S2. Primer sequences used to construct yeast recombinant plasmids. Table S3. Primer sequences used in qRT-PCR. Table S4. List of differentially expressed genes in the OE5 compared to Col-0 Arabidopsis plants under normal conditions. Table S5. List of differentially expressed genes in the OE5 compared to Col-0 Arabidopsis plants under salt stress conditions. Table S6. The primer sequences of qRT-PCR for validation of the selected DEGs. 
Author Contributions: X.J. and Y.W. designed the research. Z.H., Z.L., H.L., and L.H. performed the experiments. Z.H., Z.L., H.L., and Z.W. analyzed the data. Z.H. and X.J. wrote the article.

Funding: This work was supported by The Fundamental Research Funds for the Central Universities (No. 2572017DA01), the National Natural Science Foundation of China (No. 31500535), and The Heilongjiang Province Science Foundation (No. QC2018017).

Acknowledgments: The authors thank the anonymous referees whose constructive comments helped to improve the quality of this work. The authors also appreciate those contributors who have made the data accessible in public databases.

Conflicts of Interest: The authors declare no conflicts of interest.

\section{References}

1. Yamaguchi-Shinozaki, K.; Shinozaki, K. Transcriptional regulatory networks in cellular responses and tolerance to dehydration and cold stresses. Annu. Rev. Plant Biol. 2006, 57, 781-803. [CrossRef] [PubMed]

2. Xiong, L.; Schumaker, K.S.; Zhu, J.K. Cell signaling during cold, drought, and salt stress. Plant Cell 2002, 14 (Suppl. 1), S165-S183. [CrossRef] [PubMed]

3. Tak, H.; Negi, S.; Ganapathi, T.R. Banana NAC transcription factor MusaNAC042 is positively associated with drought and salinity tolerance. Protoplasma 2017, 254, 803-816. [CrossRef] [PubMed]

4. Liu, Y.; Ji, X.; Nie, X.; Qu, M.; Zheng, L.; Tan, Z.; Zhao, H.; Huo, L.; Liu, S.; Zhang, B.; et al. Arabidopsis AtbHLH112 regulates the expression of genes involved in abiotic stress tolerance by binding to their E-box and GCG-box motifs. New Phytol. 2015, 207, 692-709. [CrossRef] [PubMed]

5. Guo, H.; Wang, Y.; Wang, L.; Hu, P.; Wang, Y.; Jia, Y.; Zhang, C.; Zhang, Y.; Zhang, Y.; Wang, C.; et al. Expression of the MYB transcription factor gene BplMYB46 affects abiotic stress tolerance and secondary cell wall deposition in Betula platyphylla. Plant Biotechnol. J. 2017, 15, 107-121. [CrossRef] [PubMed]

6. Zhu, D.; Hou, L.; Xiao, P.; Guo, Y.; Deyholos, M.K.; Liu, X. VvWRKY30, a grape WRKY transcription factor, plays a positive regulatory role under salinity stress. Plant Sci. 2019, 280, 132-142. [CrossRef]

7. Kumar, M.; Lee, S.C.; Kim, J.Y.; Kim, S.J.; Aye, S.S.; Kim, S.R. Over-expression of dehydrin gene, Osdhn1, improves drought and salt stress tolerance through scavenging of reactive oxygen species in rice (Oryza sativa L.). J. Plant Biol. 2014, 57, 383-393. [CrossRef]

8. Ijaz, R.; Ejaz, J.; Gao, S.; Liu, T.; Imtiaz, M.; Ye, Z.; Wang, T. Overexpression of annexin gene AnnSp2, enhances drought and salt tolerance through modulation of ABA synthesis and scavenging ROS in tomato. Sci. Rep. 2017, 7, 12087. [CrossRef]

9. Puranik, S.; Sahu, P.P.; Srivastava, P.S.; Prasad, M. NAC proteins: Regulation and role in stress tolerance. Trends Plant Sci. 2012, 17, 369-381. [CrossRef]

10. Riechmann, J.L.; Heard, J.; Martin, G.; Reuber, L.; Jiang, C.; Keddie, J.; Adam, L.; Pineda, O.; Ratcliffe, O.J.; Samaha, R.R.; et al. Arabidopsis transcription factors: Genome-wide comparative analysis among eukaryotes. Science 2000, 290, 2105-2110. [CrossRef]

11. Tran, L.S.; Nishiyama, R.; Yamaguchi-Shinozaki, K.; Shinozaki, K. Potential utilization of NAC transcription factors to enhance abiotic stress tolerance in plants by biotechnological approach. G.M. Crops 2010, 1, 32-39. [CrossRef] [PubMed]

12. Nuruzzaman, M.; Sharoni, A.M.; Kikuchi, S. Roles of NAC transcription factors in the regulation of biotic and abiotic stress responses in plants. Front. Microbiol. 2013, 4, 248. [CrossRef] [PubMed]

13. Nakashima, K.; Takasaki, H.; Mizoi, J.; Shinozaki, K.; Yamaguchi-Shinozaki, K. NAC transcription factors in plant abiotic stress responses. Biochim. Biophys. Acta. 2012, 1819, 97-103. [CrossRef] [PubMed]

14. Jiang, Y.; Deyholos, M.K. Comprehensive transcriptional profiling of $\mathrm{NaCl}$ stressed Arabidopsis roots reveals novel classes of responsive genes. BMC Plant Biol. 2006, 6, 25. [CrossRef] [PubMed]

15. Nuruzzaman, M.; Sharoni, A.M.; Satoh, K.; Karim, M.R.; Harikrishna, J.A.; Shimizu, T.; Sasaya, T.; Omura, T.; Haque, M.A.; Hasan, S.M.; et al. NAC transcription factor family genes are differentially expressed in rice during infections with Rice dwarf virus, Rice black-streaked dwarf virus, Rice grassy stunt virus, Rice ragged stunt virus, and Rice transitory yellowing virus. Front. Plant Sci. 2015, 6, 676. [CrossRef] [PubMed]

16. Fujita, M.; Fujita, Y.; Maruyama, K.; Seki, M.; Hiratsu, K.; Ohme-Takagi, M.; Tran, L.S.; Yamaguchi-Shinozaki, K.; Shinozaki, K. Adehydration-induced NAC protein, RD26, is involved in a novel ABA-dependent stress-signaling pathway. Plant J. 2004, 39, 863-876. [CrossRef] [PubMed] 
17. Tran, L.S.; Nakashima, K.; Sakuma, Y.; Simpson, S.D.; Fujita, Y.; Maruyama, K.; Fujita, M.; Seki, M.; Shinozaki, K.; Yamaguchi-Shinozaki, K. Isolation and functional analysis of Arabidopsis stress-inducible NAC transcription factors that bind to a drought-responsive cis-element in the early responsive to dehydration stress 1 promoter. Plant Cell 2004, 16, 2481-2498. [CrossRef] [PubMed]

18. Hu, H.; You, J.; Fang, Y.; Zhu, X.; Qi, Z.; Xiong, L. Characterization of transcription factor gene SNAC2 conferring cold and salt tolerance in rice. Plant Mol. Biol. 2008, 67, 169-181. [CrossRef]

19. Fang, Y.; Liao, K.; Du, H.; Xu, Y.; Song, H.; Li, X.; Xiong, L. A stress responsive NAC transcription factor SNAC3 confers heat and drought tolerance through modulation of reactive oxygen species in rice. J. Exp. Bot. 2015, 66, 6803-6817. [CrossRef]

20. Lee, D.K.; Chung, P.J.; Jeong, J.S.; Jang, G.; Bang, S.W.; Jung, H.; Kim, Y.S.; Ha, S.H.; Choi, Y.D.; Kim, J.K. The rice OsNAC6 transcription factor orchestrates multiple molecular mechanisms involving root structural adaptions and nicotianamine biosynthesis for drought tolerance. Plant Biotechnol. J. 2017, 15, 754-764. [CrossRef]

21. Shim, J.S.; Oh, N.; Chung, P.J.; Kim, Y.S.; Choi, Y.D.; Kim, J.K. Overexpression of OsNAC14 Improves Drought Tolerance in Rice. Front. Plant Sci. 2018, 9, 310. [CrossRef] [PubMed]

22. Nakashima, K.; Tran, L.S.; Van Nguyen, D.; Fujita, M.; Maruyama, K.; Todaka, D.; Ito, Y.; Hayashi, N.; Shinozaki, K.; Yamaguchi-Shinozaki, K. Functional analysis of a NAC-type transcription factor OsNAC6 involved in abiotic and biotic stress-responsive gene expression in rice. Plant J. 2007, 51, 617-630. [CrossRef] [PubMed]

23. Xue, G.P.; Way, H.M.; Richardson, T.; Drenth, J.; Joyce, P.A.; McIntyre, C.L. Overexpression of TaNAC69 leads to enhanced transcript levels of stress up-regulated genes and dehydration tolerance in bread wheat. Mol. Plant 2011, 4, 697-712. [CrossRef] [PubMed]

24. Liu, C.; Wang, B.; Li, Z.; Peng, Z.; Zhang, J. TsNAC1 Is a Key Transcription Factor in Abiotic Stress Resistance and Growth. Plant Physiol. 2018, 176, 742-756. [CrossRef] [PubMed]

25. Negi, S.; Tak, H.; Ganapathi, T.R. Expression analysis of MusaNAC68 transcription factor and its functional analysis by overexpression in transgenic banana plants. Plant Cell Tiss. Organ Cult. 2016, 125, 59-70. [CrossRef]

26. Jia, D.; Jiang, Q.; van Nocker, S.; Gong, X.; Ma, F. An apple (Malus domestica) NAC transcription factor enhances drought tolerance in transgenic apple plants. Plant Physiol Biochem. 2019, 139, 504-512. [CrossRef] [PubMed]

27. Wang, C.; Gao, C.; Wang, L.; Zheng, L.; Yang, C.; Wang, Y. Comprehensive transcriptional profiling of NaHCO3-stressed Tamarix hispida roots reveals networks of responsive genes. Plant Mol. Biol. 2014, 84, 145-157. [CrossRef]

28. Demidchik, V.; Straltsova, D.; Medvedev, S.S.; Pozhvanov, G.A.; Sokolik, A.; Yurin, V. Stress-induced electrolyte leakage: The role of $\mathrm{K}^{+}$-permeable channels and involvement in programmed cell death and metabolic adjustment. J. Exp. Bot. 2014, 65, 1259-1270. [CrossRef]

29. Hao, Y.J.; Song, Q.X.; Chen, H.W.; Zou, H.F.; Wei, W.; Kang, X.S.; Ma, B.; Zhang, W.K.; Zhang, J.S.; Chen, S.Y. Plant NAC-type transcription factor proteins contain a NARD domain for repression of transcriptional activation. Planta 2010, 232, 1033-1043. [CrossRef]

30. Petrov, V.; Hille, J.; Mueller-Roeber, B.; Gechev, T.S. ROS-mediated abiotic stress-induced programmed cell death in plants. Front. Plant Sci. 2015, 6, 69. [CrossRef]

31. Zang, D.; Wang, L.; Zhang, Y.; Zhao, H.; Wang, Y. ThDof1.4 and ThZFP1 constitute a transcriptional regulatory cascade involved in salt or osmotic stress in Tamarix hispida. Plant Mol. Biol. 2017, 94, 495-507. [CrossRef] [PubMed]

32. Li, Y.; Chu, Z.; Luo, J.; Zhou, Y.; Cai, Y.; Lu, Y.; Xia, J.; Kuang, H.; Ye, Z.; Ouyang, B. The C2H2 zinc-finger protein SIZF3 regulates AsA synthesis and salt tolerance by interacting with CSN5B. Plant Biotechnol. J. 2018, 16, 1201-1213. [CrossRef] [PubMed]

33. Mao, C.; Ding, J.; Zhang, B.; Xi, D.; Ming, F. OsNAC2 positively affects salt-induced cell death and binds to the OsAP37 and OsCOX11 promoters. Plant J. 2018, 94, 454-468. [CrossRef]

34. Wang, L.; Li, Z.; Lu, M.; Wang, Y. ThNAC13, a NAC Transcription Factor from Tamarix hispida, Confers Salt and Osmotic Stress Tolerance to Transgenic Tamarix and Arabidopsis. Front. Plant Sci. 2017, 8, 635. [CrossRef] [PubMed] 
35. Niu, F.; Wang, C.; Yan, J.; Guo, X.; Wu, F.; Yang, B.; Deyholos, M.K.; Jiang, Y.Q. Functional characterization of NAC55 transcription factor from oilseed rape (Brassica napus L.) as a novel transcriptional activator modulating reactive oxygen species accumulation and cell death. Plant Mol. Biol. 2016, 92, 89-104. [CrossRef] [PubMed]

36. Jin, C.; Li, K.Q.; Xu, X.Y.; Zhang, H.P.; Chen, H.X.; Chen, Y.H.; Hao, J.; Wang, Y.; Huang, X.S.; Zhang, S.L. A Novel NAC Transcription Factor, PbeNAC1, of Pyrus betulifolia Confers Cold and Drought Tolerance via Interacting with PbeDREBs and Activating the Expression of Stress-Responsive Genes. Front. Plant Sci. 2017, 8, 1049. [CrossRef] [PubMed]

37. Yan, J.; Tong, T.; Li, X.; Chen, Q.; Dai, M.; Niu, F.; Yang, M.; Deyholos, M.K.; Yang, B.; Jiang, Y.Q. A Novel NAC-Type Transcription Factor, NAC87, from Oilseed Rape Modulates Reactive Oxygen Species Accumulation and Cell Death. Plant Cell Physiol. 2018, 59, 290-303. [CrossRef] [PubMed]

38. Silva-Ortega, C.O.; Ochoa-Alfaro, A.E.; Reyes-Agüero, J.A.; Aguado-Santacruz, G.A.; Jiménez-Bremont, J.F. Salt stress increases the expression of Pp5Ccs gene and induces proline accumulation in cactus pear. Plant Physiol. Biochem. 2008, 46, 82-92. [CrossRef] [PubMed]

39. Kavi Kishor, P.B.; Sreenivasulu, N. Is proline accumulation per se correlated with stress tolerance or is proline homeostasis a more critical issue? Plant Cell Environ. 2014, 37, 300-311. [CrossRef]

40. Forrest, K.L.; Bhave, M. Major intrinsic proteins (MIPs) in plants: A complex gene family with major impacts on plant phenotype. Funct. Integr. Genomics 2007, 7, 263-289. [CrossRef]

41. Guo, L.; Wang, Z.Y.; Lin, H.; Cui, W.E.; Chen, J.; Liu, M.; Chen, Z.L.; Qu, L.J.; Gu, H. Expression and functional analysis of the rice plasma-membrane intrinsic protein gene family. Cell Res. 2006, 16, 277-286. [CrossRef] [PubMed]

42. Park, C.J.; Shin, R.; Park, J.M.; Lee, G.J.; You, J.S.; Paek, K.H. Induction of pepper cDNA encoding a lipid transfer protein during the resistance response to tobacco mosaic virus. Plant Mol. Biol. 2002, 48, 243-254. [CrossRef] [PubMed]

43. Cameron, K.D.; Teece, M.A.; Smart, L.B. Increased accumulation of cuticular wax and expression of lipid transfer protein in response to periodic drying events in leaves of tree tobacco. Plant Physiol. 2006, 140, 176-183. [CrossRef] [PubMed]

44. Guo, L.; Yang, H.; Zhang, X.; Yang, S. Lipid transfer protein 3 as a target of MYB96 mediates freezing and drought stress in Arabidopsis. J. Exp. Bot. 2013, 64, 1755-1767. [CrossRef] [PubMed]

45. Zhu, Q.; Zhang, J.; Gao, X.; Tong, J.; Xiao, L.; Li, W.; Zhang, H. The Arabidopsis AP2/ERF transcription factor RAP2.6 participates in ABA, salt and osmotic stress responses. Gene 2010, 457, 1-12. [CrossRef] [PubMed]

46. Krishnaswamy, S.; Verma, S.; Rahman, M.H.; Kav, N.N. Functional characterization of four APETALA2-family genes (RAP2.6, RAP2.6L, DREB19 and DREB26) in Arabidopsis. Plant Mol. Biol. 2011, 75, 107-127. [CrossRef] [PubMed]

47. Pandey, G.K.; Grant, J.J.; Cheong, Y.H.; Kim, B.G.; Li, L.; Luan, S. ABR1, an APETALA2-domain transcription factor that functions as a repressor of ABA response in Arabidopsis. Plant Physiol. 2005, 139, 1185-1193. [CrossRef]

48. Song, C.; Je, J.; Hong, J.K.; Lim, C.O. Ectopic expression of an Arabidopsis dehydration-responsive element-binding factor DREB2C improves salt stress tolerance in crucifers. Plant Cell Rep. 2014, 33, 1239-1254. [CrossRef]

49. Babitha, K.C.; Ramu, S.V.; Pruthvi, V.; Mahesh, P.; Nataraja, K.N.; Udayakumar, M. Co-expression of AtbHLH17 and AtWRKY28 confers resistance to abiotic stress in Arabidopsis. Transgenic Res. 2013, 22, 327-341. [CrossRef]

50. Balazadeh, S.; Siddiqui, H.; Allu, A.D.; Matallana-Ramirez, L.P.; Caldana, C.; Mehrnia, M.; Zanor, M.I.; Köhler, B.; Mueller-Roeber, B. A gene regulatory network controlled by the NAC transcription factor ANAC092/AtNAC2/ORE1 during salt-promoted senescence. Plant J. 2010, 62, 250-264. [CrossRef]

51. Ji, X.Y.; Zheng, L.; Liu, Y.J.; Nie, X.G.; Liu, S.N.; Wang, Y.C. A transient transformation system for the functional characterization of genes involved in stress response. Plant Mol. Biol. Rep. 2014, 32, 732-739. [CrossRef]

52. Clough, S.J.; Bent, A.F. Floral dip: A simplified method for Agrobacterium-mediated transformation of Arabidopsis thaliana. Plant J. 1998, 16, 735-743. [CrossRef] [PubMed]

53. Lichtenthaler, H.K. Chlorophylls and carotenoids: Pigments of photosynthetic biomembranes. Methods Enzymol. 1987, 148, 350-382. [CrossRef] 
54. Fryer, M.J.; Oxborough, K.; Mullineaux, P.M.; Baker, N.R. Imaging of photo-oxidative stress responses in leaves. J. Exp. Bot. 2002, 53, 1249-1254. [CrossRef] [PubMed]

55. Zhang, X.; Wang, L.; Meng, H.; Wen, H.; Fan, Y.; Zhao, J. Maize ABP9 enhances tolerance to multiple stresses in transgenic Arabidopsis by modulating ABA signaling and cellular levels of reactive oxygen species. Plant Mol. Biol. 2011, 75, 365-378. [CrossRef] [PubMed]

56. Wang, L.; Feng, Z.; Wang, X.; Wang, X.; Zhang, X. DEGseq: A R package for identifying differentially expressed genes from RNA-seq data. Bioinformatics 2010, 26, 136-138. [CrossRef]

57. Dal Santo, S.; Stampfl, H.; Krasensky, J.; Kempa, S.; Gibon, Y.; Petutschnig, E.; Rozhon, W.; Heuck, A.; Clausen, T.; Jonak, C. Stress-induced GSK3 regulates the redox stress response by phosphorylating glucose-6-phosphate dehydrogenase in Arabidopsis. Plant Cell 2012, 24, 3380-3392. [CrossRef]

58. Bates, L.S.; Waldren, R.P.; Teare, I.D. Rapid determination of free proline for water-stress studies. Plant Soil 1973, 39, 205-207. [CrossRef]

59. Livak, K.J.; Schmittgen, T.D. Analysis of relative gene expression data using real-time quantitative PCR and the $2^{-\Delta \Delta C t}$ method. Methods 2001, 25, 402-408. [CrossRef]

60. Wang, Y.; Gao, C.; Liang, Y.; Wang, C.; Yang, C.; Liu, G. A novel bZIP gene from Tamarix hispida mediates physiological responses to salt stress in tobacco plants. J. Plant Physiol. 2010, 167, 222-230. [CrossRef]

(C) 2019 by the authors. Licensee MDPI, Basel, Switzerland. This article is an open access article distributed under the terms and conditions of the Creative Commons Attribution (CC BY) license (http://creativecommons.org/licenses/by/4.0/). 